\title{
CANADIAN JOURNAL OF EDUCATIONAL COMMUNICATION
}

Volume 19, Number 2, Summer 1990

ISSN $0710-4340$

Des activités cognitives et métacognitives conçues pour développer l'autonomie des étudiants adultes dans un cours en enseignement à distance

André-Jacques Deschênes Louise Bourdages

Céline Lebel Bernard Michaud

Intelligent Tutoring Systems: A Review For Beginners Peter Holt Peter Wood

Conceptualizing Hypermedia Curricula For Literary Studies In Schools Alister Cumming Gerrl SInclair

Saying "NO" To Computers In The Classroom Randle W. Nelsen

Saying "YES" to Educational Technology: A Response to Nelsen's "NO"

Robert J. D. Jones

\section{An AMTEC Publication}




\section{EDITORIAL BOARD}

\section{Cheryl Amundsen}

McGill University

Gary J. Anglin

University of Kentucky

Jon Baggaley

Concordia University

Robert M. Bemard

Concordia University

F. Barry Brown

University of Saskatchewan

Bruce Clark

University of Calgary

Dan Coldeway

Athabasca University

Bemard Dubreull

Concordia University

D. J. Engel

University of Alberta

Garfield Fizzard

Memorial University of Newfoundland

George L Gels

OISE

Michael Hannafin

Florida State University

William Hanson

Calgary Board of Education

Denis Hlynka

University of Manitoba

W. J. Hunter

University of Calgary

Robert J ones

Sheridan College of Applied

Arts and Technology

Lome Koroluk

University of British Columbia

James J . LaFollette

University of Alberta

Richard F. Lewis

University of Windsor

David A. Mappin

University of Alberta
Earl R. Misanchuk

University of Saskatchewan

Ronald Owston

York University

Lauran Sandals

University of Calgary

Louise Sa uve

Tele-Universite

Richard F. Schmid

Concordia University

R. J. Schmidt

Stathcona County Board of

Education

Marlela Tovar

Concordia University

Ronald Vlaw

Universite de Sherbrooke

Laura Winer

APO Quebec

Clayton R. Wright

Grant MacEwan Community College

AMTEC BOARD OF DIRECTORS

President

Bruce MacLean

Vancouver Community College

Past President

Mary Kennedy

Memorial University

President Eect

David Mappin

University of Alberta

Secretary / Tieasurer

Al LeBlanc

Separate School Board Sault Ste. Marie

Director

Margaret Sadler

University of Alberta

Director

John Godfreyson

School District \#68 Nanaimo, B.C.

Director

Esio Marzotto

University of

Membership

Dove Bleman

Huron County Board of Education 


\section{Canadian Joumal of Educational Communic ation}

\author{
Volume 19, Number 2 \\ Summer 1990
}

\section{Editor}

Richard A. Schwier

\section{Editoral Assistant}

Patricia Nickel-St. Onge

\section{Production Manager \\ Mary Genova, WRITEWORKS}

ISSN $0710 \cdot 4340$

The Canadlan Joumal of Educational Communication Is published by the Association for Medla and Technology In Education in Canada; 3-1750 The Queensway, Sulte 1318, Etoblcoke, Ontario M9C 5H5; Attention: Mr. Al LeBlanc, Secretary/Trea surer. Notification of address change should be sent to the above. All articles are copyright by AMTEC and may be reproduced for nonprofit use without permlsslon provided credit is given to CJEC. Back lssues of CJEC are $\$ 15$ Canadian and may be obtained by contactling the Editor. CJEC Is indexed In the Canadian Education Index and ERIC.

Second Class Mail Registration No. 6956

IN THENEXT ISSUE: Integrating Research Into Instructional Practice: The Use and Abuse of Meta-Analysis, R. M. Bemard \&SNaidu

Effects of Students' Prior Knowledge and Presentation Mode on Achievement (visual/verbal testing) of Different Educational Objectives. F. M. Dwyer \& C. A. Dwyer.

Themex: An Educational Expert System for Thermo-Dynamics Sudents, B. Marcos, K. Lundgren, A. Boily, L Therien, J . Lapoint, \& M. Vellette.

An Anthropological View of Educational Communications and Technology. Beliefs and Behaviours in Research and Theory. A. R J Yeoman.

\section{ARTICLES}

Des activites cognitives et metacognitives concues pour developper l'autonomie des etudiants adultes dansun cours en enseignement a distance

\section{Andre-Jacques Deschenes Louise Bourdages Ce'ne Lebel \\ Bemard Michaud}

Intelligent Tutoring Systems:

A Review for Beginners

\section{Peter Holt}

Peter Wood

Conceptualizing Hypermedia

Cumicula for Literary Studies

in Schools

\section{Alister Cumming \\ Gemi Sinclair}

\section{POINT}

Saying "NO" to Computers

in the Classroom

\section{Randle W. Nelsen}

\section{COUNTER-POINT}

Saying 'YES" to Educational

Technology: A Response to

Nelsen's "NO"

MICROWARE REVIEW

\section{BOOK REVIEWS}

All correspondence should be addressed to:

Dr. Richard A. Schwier, Editor Communic ations/Continuing

\& Vocational Education College of Education University of Saskatchew Sa skatoon, Sa skatchewan S7N OWO 


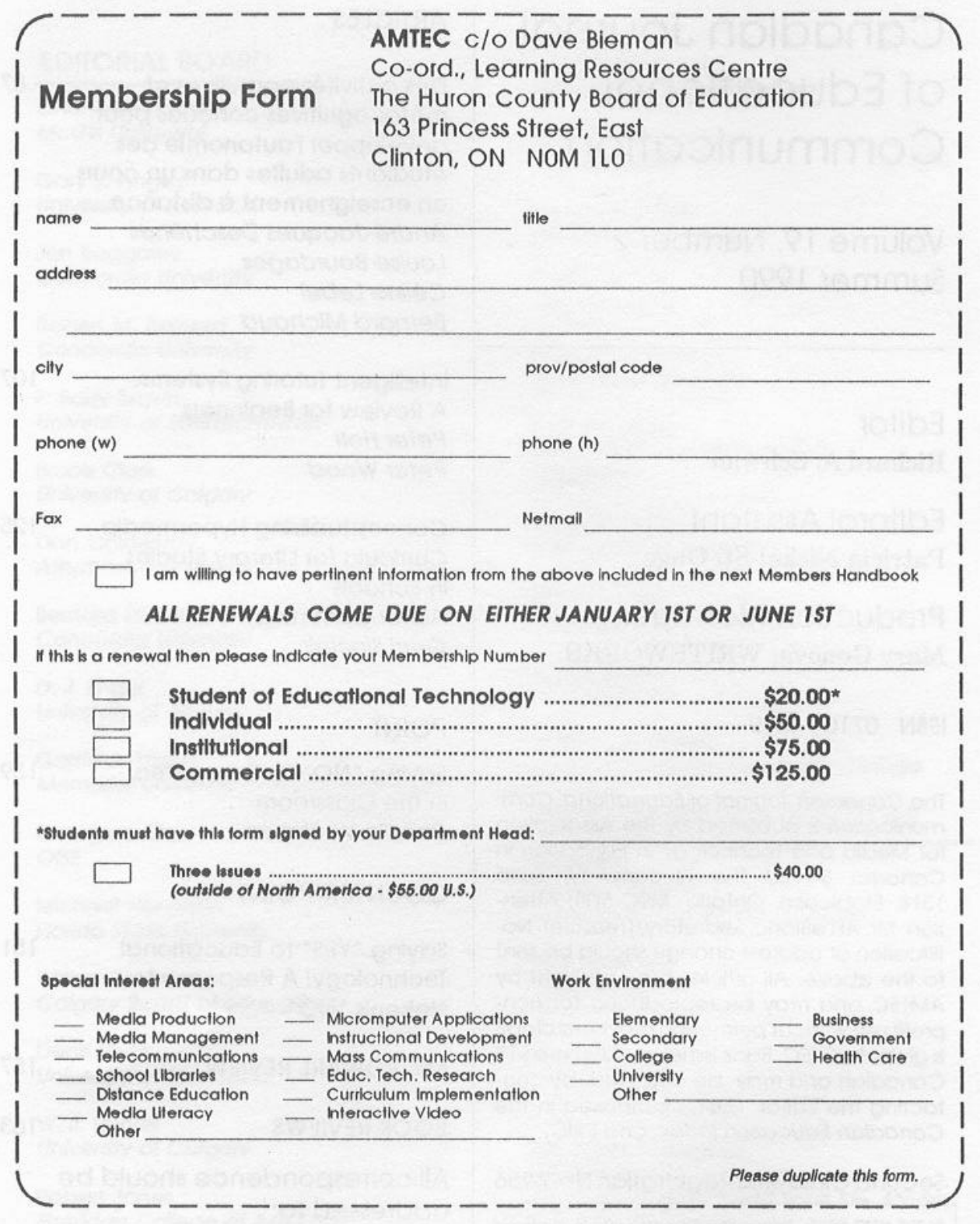

CJEC is typeset on an Apple Macintosh Plus $^{n m}$ in PageMaker 3.0 ${ }^{n t}$. Galley proofs to authors and final cameraready impressions are output on a Qume CrystalPrint ${ }^{\mathrm{TM}}$ Publisher.

Concordia University Printing Services

\section{Acknowledgement}

The Canadian Journal of Educational Communication is supported by a grant from the Social Sciences and Humanities Research Council of Canada. 


\title{
Des activités cognitives et méta- cognitives conçues pour développer l'autonomie des étudiants adultes dans un cours en enseignement à distance ${ }^{1}$
}

\author{
André-Jacques Deschênes \\ Louise Bourdages
}

\author{
Céline Lebel \\ Bemard Michaud
}

\begin{abstract}
Résumé: L'utillsation d'activités comme support à l'apprentissage en formation à distance pose des questions que la recherche commence à peine à explorer. Certains auteurs suggèrent de proposer des activités de type métacognitif pour faciliter la démarche autonome des étudiants. En utilisant un cadre générall décrivant l'autonomie comme la gestion de son activité cognitive, nous avons analysé les activités cognitives et métacognitives d'un cours à distance par rapport aux aspects personne, stratégies et tâches à réaliser. Nous constatons que le concepteur utilse deux façons distinctes de promouvoir le développement de l'autonomie des étudiants. D'une part, il propose, avec les activités, des descriptions portant sur les objectifs et les tâches à réa liser qui constituent des informations correspondant à des connaissances de type méta cognitif. Ces conna issances sont nécessa ires à la gestion de la situation d'apprentissage. D'autre part il foumit des activités où l'étudiant doit: 1) planifier son temps en fonction de ses objectifs et des contenus théoriques présentés dans le cours, 2) faire le point sur la démarche réalisée pour s'ajuster s'il y a lieu et, 3) évaluer ses acquis et le déroulement de son activité. II suggére aussi des activités qui permettent à l'étudiant d'identifier plusieurs caractéristiques de la situation d'apprentissage. Ces connaissances et les stratégies mises en oeuvre lors de ces activités assurent la gestion de l'apprentissage et offrent ainsi une démarche pédagogique où progressivement l'étudiant est amené à prendre en charge son activité cognitive et à la gérer de façon efficace.
\end{abstract}

L'utilisation d'activités d'apprentissage pour supporter la démarche des étudiants, même si elle est très répandue dans la pratique de l'enseignement à distance, pose des questions que la recherche commence à peine à aborder. Par exemple, on peut se demander quel type d'activités est le plus efficace quels rôles jouent ces activités dans l'apprentissage, quels critères utiliser pour choisir des activités, etc. Une recension des écrits sur le sujet (Landry, 1987) "montre la rareté et la faiblesse des travaux sur le role des activités d'apprentissage dans l'acquisition de connaissances à l'aide de documents écrits. Par conséquent, la pratique largement répandue en enseignement à distance de fournir avec les textes un cahier d'activités s'appuie sur bien peu de données empiriques démontrant l'utilité ou la rentabilité de ces exercices. La revue de littérature ne fournit pas non plus de réponse aux questions 
portant sur le type d'activités proposées, leur nombre et le fait de fournir ou non un corrigé aux activités" (Deschênes, Bourdages, Lebel et Michaud, 1988, p. $102)$.

La seule étude empirique que nous connaissons qui s'intéresse à ces questions est celle de Benko de Rotaeche (1987). L'auteures compare l'apprentissage des étudiants à la suite de la lecture de trois versions différentes d'un même document: l'une sans activité d'apprentissage, une autre avec des activités d'apprentissage présentées dans un cahier différent de celui du texte à lire et une troisième avec des activités d'apprentissage insérées à l'intérieur du même document que celui du texte à lire. Les résultats obtenus démontrent que la troisième version produit des performances supérieures aux deux autres, Cette analyse est par ailleurs très globale et laisse toujours sans réponse plusieurs des questions soulevées.

C'est dans le contexte de cette problématique que nous avons amorcé une série de travaux ${ }^{2}$ destinés, entre autres, à étudier la pratique des concepteurs de cours à distance dans le but de proposer éventuellement une typologie des activités d'apprentissage et des critères pour les sélectionner selon les objectifs visés. L'analyse que nous présenterons s'intéresse de façon particulière aux activités de type métacognitif proposées dans un cours à distance de la Téléuniversité. Ces activités renvoient au concept d'autonomie (Deschênes, 1989) souvent associé à la formation à distance.

L'enseignement à distance place en effet les étudiants dans une situation qui se distingue de celle des étudiants sur campus et se rapproche, par certaines de sea caractéristiques, d'une situation coutumière d'étude. Alors que les étudiants sur campus sont généralement en contact direct avec leur professeur, qu'ils sont fréquemment mis en situation de communication avec leurs collègues étudiants et qu'ils ont facilement, accès à tous les services pédagogiques de support à leur apprentissage, les étudiants à distance se trouvent isolés, responsables des contacts nécessaires pour mener à bien leur travail, seuls à planifier leur étude, à maintenir leur motivation, etc.

Cette situation ressemble à une tâche typique d'étude (sur campus), selon la description qu'en font Thomas et Rohwer (1986), où l'étudiant se doit de contrôler à peu près tous les aspects de la situation. Non seulement doit-il s'assurer que les informations à acquérir le soient de façon satisfaisante, mais il doit aussi prendre en charge sa motivation, la gestion de son temps et l'aménagement de son environnement. En fait, quel que soit l'encadrement pédagogique fourni, l'apprentissage à distance suppose au minimum que les tâches à réaliser le soient dans un lieu ou un temps non prévu par le concepteur du cours.

On comprend ainsi que certains auteurs (Henri et Raye, 1985; Henri et Lescop, 1988; Hostler, 1986) caractérisent l'enseignement à distance par l'autonomie que ce système laisse aux étudiants. Il s'agit en fait davantage d'une caractéristique de l'apprentissage à distance que l'on peut trouver dans n'importe quel type d'enseignement, dans la mesure où il est demandé aux étudiants de réaliser seuls, sans le support direct du professeur, des travaux 
ou de l'étude en vue de l'acquisition de connaissances. Evidemment, sur campus, la présence en salle de cours, les contacts fréquents avec le professeur et les autres collègues font que l'étudiant a accès de façon immédiate et régulière (à l'initiative des autres souvent) à toutes une gamme de services formels et informels pouvant l'aider dans sa démarche. Ce n'est assurément pas le cas en enseignement à distance où l'étudiant rencontre rarement le professeur et ne connait pas, la plupart du temps, les autres étudiants de son groupe. Son isolement, parfois géographique, souvent psychologique, fait que tout son travail se réalise à peu près exclusivement avec le matériel fourni par l'institution de télé-enseignement, sans aucun contact direct important avec d'autres personnes.

S'il ne s'agit pas à proprement parler, d'un apprentissage autodidactique ${ }^{3}$, on peut cependant reconnaitre que c'est une situation d'apprentissage "autodirigée" (Holmberg, 1974), où l'essentiel des objectifs et des contenus est déterminé par un concepteur, mais où l'étudiant doit prendre en charge une partie des moyens à mettre en oeuvre pour réaliser les apprentissages proposes, planifier son temps, choisir son environnement, diriger et maintenir sa motivation. On peut donc parler d'un minimum d'autonomie nécessaire lorsqu'on se retrouve dans un système de télé-enseignement.

L'utilisation du terme autonomie renvoie à des conceptions fort diverses et pose de ce fait un certain nombre de difficultés. Deschênes (1989) a discuté de cette question et utilise les concepts de la psychologie cognitive pour définir l'autonomie comme la gestion de son activité d'apprentissage. L'autonomie renvoie ainsi à la notion de métacognition qui comprend des connaissances portant sur les aspects personnes, tâches et stratégies associes à l'activité cognitive et le controle de cette activité (Baker et Brown, 1984a et 1984b; Flavell, 1981 et 1985; Kurtz, à paraître; Pinard, 1987; Pinard, Bibeau et LefebvrePinard, 1985).

Dans cette perspective, l'autonomie n'est pas, comme le prétendent Garrison et Baynton (1987), la "liberté" de choisir ses objectifs d'apprentissage, ses activités d'apprentissage et ses méthodes d'évaluation; ce sont là plutôt des façons d'exercer son autonomie. Elle repose davantage sur le fait que l'étudiant assume, à quelque degré que ce soit, la prise en charge du déroulement de son activité d'apprentissage. Par rapport aux objectifs, ce peut être non seulement de choisir ses objectifs d'apprentissage, mais aussi de se situer par rapport à des objectifs d'apprentissage définis à l'avance par un concepteur, d'évaluer le degré d'atteinte des objectifs visés, d'ordonner des objectifs d'apprentissage, etc. Pour ce faire l'étudiant doit posséder des connaissances sur le rôle des objectifs d'apprentissage dans une situation d'enseignement, sur la façon de se fixer des objectifs d'apprentissage, de les évaluer et de les réajuster.

L'autonomie exige donc un minimum de connaissance et d'habiletés que tous les étudiants, même adultes, n'ont pas nécessairement développées. Il n'est pas assuré en effet que tous les individus ontappris comment apprendre et on observe souvent que plusieurs adultes se sentent inadéquats devant une tâche cognitive (Hostler, 1986). En conséquence, si l'on veut supporter la 
démarche autonome des étudiants, il importe de leur fournir des moyens leur permettant d'exercer une gestion efficace de leurs tâches cognitives.

Deschênes, Bourdages, Lebel et Michaud (à paraître) suggèrent d'ajouter, dans un cours à distance, aux activités cognitives assurant la maîtrise des contenus présentes, des activités de type métacognitif pouvant permettre aux étudiants de gérer leur situation d'apprentissage. On sait par ailleurs, qu'il faut rendre explicites à l'étudiant, des connaissances portant sur les personnes, les tâches et les stratégies de telle sorte qu'il puisse prendre des décisions éclairées sur la planification, la régulation et l'évaluation de son activité cognitive. Lorsqu'il s'agit de stratégies, par exemple, il importe de faire connaître à l'étudiant des techniques de lecture ou d'étude et de lui communiquer quand, comment et pourquoi ces stratégies peuvent lui être utiles. Pressley, Borkowsky et O'Sullivan (1984) ont en effet observé que si on explicite l'utilisation des stratégies, leur maintien et leur généralisation à d'autres situations d'apprentissage sont meilleurs. La conscience de ses ressources et de ses faiblesses comme apprenant (personnes), la connaissance des caractéristiques des tâches cognitives (tâches) et des "quand, comment et pourquoi" utiliser les diverses stratégies (stratégies) constitutent pour Armbruster et Brown (1984) un prérequis à la gestion de son activité cognitive. Et cela s'apprend et peut être enseigné... (Brown, Palincsar et Armbruster, 1984; Davey, 1986; Langer, 1986; Paris et Jacobs, 1984; Stewart et Tei, 1983).

Deschênes et collaborateurs, (1989) ont conçu un cours à distance dans lequel des activités de type métacognitif sont offertes aux étudiants prétendant favoriser ainsi la prise en charge de leur démarche d'apprentissage. Nous avons analysé, dans le cadre d'un projet de recherche portant sur le rôle des activités d'apprentissage dans l'acquisition des connaissances à l'aide de documents écrits(4), les activités proposées dans ce cours et nous présentons ici une partie de cette analyse en regard de cette conception de l'autonomie.

\section{L'ANALYSE DU COURS VIE QUOTIDIENNE ET SANTÉ MENTALE (PSY 2040)}

\section{Le cours}

Dans le cadre de notre projet de recherche, ce cours a été retenu pour analyse parce qu'il répondait aux critères suivants:

1) avoir été édité récemment (le cours est paru à l'été 1989);

2 ) viser des objectifs d'acquisition de connaissances (et non pas d'habiletés);

3) proposer plusieurs activités d'apprentissage; et

4) utiliser des documents écrits comme véhicule privilégié de transmission de connaissances (et non des documents audio ou audiovisuels). 
Ce cours a été conçu à la Télé-université et présente des connaissances catégorisées dans le domaine des sciences humaines.

Vie quotidienne et santé mentale vise l'acquisition de connaissances en psychologie et porte sur les concepts de prévention et de promotion en santé mentale ainsi que sur les ressources et les stratégies pour faire de la prévention ou de la promotion.

Le cours comprend un document $(28 \mathrm{~cm} \times 21,5 \mathrm{~cm})$ de 656 pages où se trouve tout le matériel nécessaire à la réalisation des apprentissages. Il comporte une première partie (20 pages) constituant une présentation générale du cours (les objectifs, les contenus, la démarche d'apprentissage, les procédures dévaluation et les informations administratives) et une deuxième partie contenant une présentation, des textes sur les informations à acquérir en santé mentale (563 pages) et les activités d'apprentissage (73 pages) insérées entre les textes.

Dans sa présentation le concepteur du cours décrit ainsi les activités d'apprentissage qu'il suggère aux étudiants:

"Pour supporter l'apprentissage et faciliter la compréhension, des activités vous sont proposées avant ou après la lecture des textes. Cependant nous croyons que vous apprendrez mieux et plus rapidement si vous gérez vous-même votre démarche d'apprentissage; pour y arriver nous vous proposons deux types d'activités: les activités M qui portent sur la démarche ellemême et les activités C qui portent sur les concepts en santé mentale. [...]

1) Les activités $M$, pour métacognitif, sont celles qui: "permettent à l'étudiant de gérer son apprentissage et d'adapter sa façon d'étudier à la situation d'enseignement à distance. Il s'agit des activités de planification, d'évaluation et de régulation de sa compréhension et de toutes les activités qui permettent à l'étudiant de tenir compte des variables environnementales.' [...]

2) Les activités $C$ pour cognitif sont celles qui: "indiquent à l'étudiant le quoi et le comment étudier. Elles peuvent lui permettre de centrer son attention sur certains éléments particuliers du contenu lui indiquant ainsi les informations importantes à retenir ou à traiter. Elles lui fournissent la façon la plus efficace de traiter les informations. Elles servent aussi à l'évaluation des connaissances. Ce sont les activités qui portent essentiellement sur le contenu à acquérir (. . .) et qui visent une meilleure compréhen sion par l'étudiant des concepts et de leur organisation."

La grille d'analyse

La grille d'analyse a été construite de façon empirique lors de l'analyse d'un premier cours de la Télé-université (Deschênes et al., 1988) et a été 
réajustée lors de l'analyse de ce cours. Elle comprend cinq (5) catégories générales, chacune se subdivisant en différentes sous-catégories. Le tableau 1 établit la liste de ces catégories et sous-catégories (5). La catégorie 1 décrit les caractéristiques générales $\mathrm{du}$ cours et de litem. La catégorie II qui porte sur la nature des objectifs en présente cinq types: cognitif, métacognitif, affectif, motivationnel et psychomoteur. Les catégories III et IV portent sur les caractéristiques de la demande et de la réponse attendue. On y distingue la nature et la forme de la demande de même que sa localisation. Quant à la réponse attendue, ses caractéristiques et celles du segment de texte où elle se trouve sont prises en compte. Enfin, la cinquième catégorie porte sur les informations fournies explicitement par le concepteur dans l'énoncé de sa demande: les objectifs, la forme et les consignes supplémentaires.

TABLEAU 1

Catégories et sous-catégories pour l'analyse des activités d'apprentissage dans des cours conçus pour le télé-enseignement

\section{RENSEIGNEMENTS GÉNÉRAUX}

1 .I Discipline

1.2 Sigle du cours

1.3 No du chapitre

1.4 No de l'activité

1.5 No item

1.6 Notation

1.7 Problème

II. NATURE DES OBJECTIFS

2.1 Cognitif

2.1.1 Domaine conceptuel

2.1.2 Méthodologique

2.1.3 Administratif

2.2 Métacognitif

2.3 Affectif

2.4 Motivationnel

2.5 Psychomoteur

III. CARACTÉRISTIQUES DE LA DEMANDE

3.1 Nature de la demande

3.2 Forme de la demande

3.3 Localisation de la demande 
IV. CARACTÉRISTIQUES DE LA RÉPONSE

4.1 Espace pour répondre

4.2 Forme de la réponse attendue

4.3 Relation question-réponse

4.4 Localisation de la réponse

4.5 Page où se trouve la réponse

4.6 Longueur du texte de la réponse

4.7 Taille du caractère

4.8 Choix de caractère

4.9 Traitement graphique

4.10 Mot à mot

V. CARACTÉRISTIQUES SELON LE CONCEPTEUR

5.1 Type

5.2 Forme

5.3 Nature de l'objectif (à partir des objectifs formulés explicitement)

5.3.1 Cognitif

5.3.2 Métacognitif

5.3.3 Affectif

5.3.4 Motivationnel

5.3.5 Psychomoteur

5.4 Consigne de réponse supplémentaire

Plusieurs des catégories et des sous-catégories de cette grille ont été conçues pour rendre compte de ce que nous observions dans les cours analysés: par exemple les catégories I Renseignements généraux et VI Caractéristiques de la réponse. D'autres trouvent leurs justifications dans la littérature en éducation, les études en compréhension de textes, en traitement de l'information et en métacognition: par exemple les catégories II Nature des objectifs et III Nature de la demande.

\section{Procédure}

Les auteurs ont lu chacun des items des activités, cherché (lorsqu'il y avait lieu) les réponses dans les textes proposés et coté chacun des items dans les sous-catégories de la grille. Toutes les décisions ont été prises par consensus.

\section{Les résultats}

Nous présenterons d'abord une vue générale des activités de ce cours, puis nous analyserons les activités selon nos critères définissant l'autonomie, les connaissances sur les personnes, les tâches et les stratégies, et les activités de type métacognitif. 


\section{Une vue générale des activités du cours}

Rappelons d'abord que, pour les fins de notre analyse, nous considérons comme une activité d'apprentissage "un ensemble d'énoncés comprenant habituellement 1) des directives sur le type ou la forme de l'activité et le comment la réaliser et, 2) des concepts faisant partie des connaissances à acquérir" (Deschênes et al., 1988, p. 103). Nous analysons les activités en les divisant en item que nous définissons comme "tout énoncé exigeant de l'étudiant une réponse écrite dans un espace prévu par le concepteur" (Deschênes et al., 1988, p. 104).

Le tableau 2 présente le nombre d'items et d'activités pour chacun des chapitres à partir des types cognitif et métacognitif définis par le concepteur. Le manuel comprend 37 activités d'apprentissage et 342 items. Il y a 29

TABLEAU 2

Nombre d'items, d'activités par chapitre selon les catégories du concepteur (PSY 2040)

\begin{tabular}{|c|c|c|c|c|c|c|}
\hline \multirow[b]{2}{*}{ Chapitre } & \multicolumn{3}{|c|}{ Activité } & \multicolumn{3}{|c|}{ Item } \\
\hline & Cognitif & $\begin{array}{l}\text { Méta- } \\
\text { cognitif }\end{array}$ & TOTAL & Cognitif & cognitif & TOTAL \\
\hline Intro. & 2 & 2 & 4 & 8 & 73 & 81 \\
\hline 1. & 0 & 0 & 0 & 0 & 0 & 0 \\
\hline 2. & 1 & 0 & 1 & 1 & 0 & 1 \\
\hline 3. & 0 & 1 & 1 & 0 & 17 & 17 \\
\hline 4. & 4 & 0 & 4 & 14 & 0 & 14 \\
\hline 5. & 1 & 0 & 1 & 1 & 0 & 1 \\
\hline 6. & 2 & 0 & 2 & 2 & 0 & 2 \\
\hline 7. & 2 & 0 & 2 & 2 & 0 & 2 \\
\hline 8. & 1 & 1 & 2 & 2 & 21 & 23 \\
\hline 9. & 3 & 1 & 4 & 10 & 48 & 58 \\
\hline 10. & 0 & 0 & 0 & 0 & 0 & 0 \\
\hline 11. & 1 & 0 & 1 & 2 & 0 & 2 \\
\hline 12. & 3 & 1 & 4 & 3 & 70 & 73 \\
\hline 13. & 1 & 0 & 1 & 2 & 0 & 2 \\
\hline 14. & 1 & 0 & 1 & 1 & 0 & 1 \\
\hline 15. & 0 & 1 & 1 & 0 & 1 & 1 \\
\hline 16. & 1 & 0 & 1 & 1 & 0 & 1 \\
\hline 17. & 2 & 0 & 2 & 9 & 0 & 9 \\
\hline 18. & 3 & 0 & 3 & 3 & 0 & 3 \\
\hline Concl. & 1 & 1 & 2 & 1 & 50 & 51 \\
\hline TOTAL & 29 & 8 & 37 & 62 & 280 & 32 \\
\hline
\end{tabular}


activités cognitives et huit métacognitives. Par ailleurs, on compte 62 items de type cognitif et 280 de type métacognitif. On retrouve des activités cognitives dans 16 des 20 chapitres (18 chapitres, l'introduction et la conclusion) alors qu'il y a des activités métacognitives dans sept chapitres. Ce tableau permet enfin de constater un regroupement des items métacognitifs; ainsi, 279 des 280 items de type métacognitifse répartissent dans sept des huit activités. Cesont des questionnaires de type vrai ou faux ou à réponses suggérées..

Le tableau 3 présente la nature de la demande pour les items cognitifs et métacognitifs. On constate que, pour les items de type cognitif, les étudiants ont à réaliser des exercices dont la forme varie (sept sous-catégories différentes) davantage que pour les items de type métacognitif (trois sous-catégories). Quant à la forme de la réponse attendue, la deuxième partie de ce tableau montre que les items de type cognitif se retrouvent dans deux sous-catégories (réponses ouvertes et tableaux à construire); les items métacognitifs quant à eux se retrouvent dans trois sous-catégories (réponses suggérées, vrai ou faux et réponses ouvertes).

TABLEAU 3

Nature de la demande et forme de la réponse attendue selon le type des items (PSY 2040)

\begin{tabular}{|c|c|c|}
\hline Nature de la demande & $\begin{array}{l}\text { Nombre } \\
\text { Cognitif }\end{array}$ & $\begin{array}{l}\text { e d'items } \\
\text { Metacognitif }\end{array}$ \\
\hline $\begin{array}{l}\text { Question } \\
\text { Résume } \\
\text { Opinion } \\
\text { Tableau } \\
\text { Synthèse } \\
\text { Analyse } \\
\text { Jugement } \\
\text { Application } \\
\text { Elaboration }\end{array}$ & $\begin{array}{r}1 \\
18 \\
0 \\
1 \\
3 \\
1 \\
0 \\
14 \\
24\end{array}$ & $\begin{array}{r}27 \\
0 \\
3 \\
0 \\
250 \\
0 \\
0\end{array}$ \\
\hline $\begin{array}{c}\text { Forme de la Réponse } \\
\text { Attendue }\end{array}$ & $\begin{array}{l}\text { Nombre } \\
\text { Cognitifs }\end{array}$ & $\begin{array}{l}\text { d'ltems } \\
\text { Métacognitifs }\end{array}$ \\
\hline $\begin{array}{l}\text { Vrai ou faux } \\
\text { (oui ou non) } \\
\text { Réponses suggérées } \\
\text { Réponse ouverte } \\
\text { Construire un tableau }\end{array}$ & $\begin{array}{r}0 \\
0 \\
59 \\
3\end{array}$ & $\begin{array}{r}70 \\
155 \\
55 \\
0\end{array}$ \\
\hline
\end{tabular}




\section{Les activités favorisant l'autonomie}

Le tableau 4 fait état de la forme de la demande. La partie inférieure du tableau se rapporte à l'un des aspects de la gestion de son activité d'apprentissage comme nous l'avons décrit plus haut. Il s'agit de connaissances portant sur les stratégies, Nous observons en effet que plusieurs des items (qui correspondent tous à des activités à un item) sont introduits ou présentés par une description qui comporte un comment et un pourquoi réaliser l'item. On observe aussi à la lecture de la présentation des activités que le concepteur introduit toujours des objectifs particuliers à chacune des activités, définit souvent la forme de l'activité et présente habituellement une démarche pour la réaliser.

\section{TABLEAU 4}

Forme de la demande pour les items selon le type ditems (PSY 2040)

\begin{tabular}{lcc}
\hline Forme de la Demande & $\begin{array}{c}\text { Nombre } \\
\text { Cognitif }\end{array}$ & $\begin{array}{l}\text { d'ltems } \\
\text { Métacognitif }\end{array}$ \\
\hline & 30 & 51 \\
Question & 3 & 0 \\
Phrase à compléter & 1 & 3 \\
Tableau & 0 & 71 \\
Vrai ou faux & 0 & 154 \\
Réponses suggérées & & \\
\hline
\end{tabular}

Combinaisons de Consignes

$\begin{array}{lc}\begin{array}{c}\text { Procédure(s) et } \\ \text { objectif(s) }\end{array} & 8 \\ \begin{array}{c}\text { Procédure(s), } \\ \text { objectif(s) et } \\ \text { définition(s) }\end{array} & 20\end{array}$

Le tableau 5 (voir page suivante) présente la nature des objectifs pour les items de type métacognitif. Un item vise des objectifs de gestion. Cent vingtcinq items permettent l'identification de connaissances (6) portant sur les trois dimensions: personnes, taches et stratégies. Les objectifs de planification et de régulation sont poursuivis par 11 et 14 items respectivement sur des aspects comme les objectifs, les tâches, le temps et les stratégies. Il y a 128 items visant l'évaluation de plusieurs aspects de la situation d'apprentissage: objectifs, stratégies, tâches, temps, etc.

Le tableau 6 (voir page 98) regroupe les mêmes items en utilisant les souscatégories des connaissances de type métacognitifdécrites par Flavell: person- 
TABLEAU 5

Nature des objectifs pour les items de type métacognitif (PSY 2040)

Objectif Nombre d'ltems

Gestion

Connaissances (Total) 125

Personnes $\quad 59$

Tâches 31

Stratégies $\quad 35$

$\begin{array}{lr}\text { Planification } & \text { (Total) } \\ \text { Objectifs } & 11 \\ \text { Stratégies } & 8 \\ \text { Taches } & 1 \\ \text { Temps } & 1 \\ \end{array}$

$\begin{array}{cr}\text { Régulation (Total) } & 14 \\ \text { Objectifs } & 12 \\ \text { Temps } & 2\end{array}$

Évaluation (Total) 129

Objectifs 2

Stratégies $\quad 51$

Taches 8

Temps 39

Connaissances $\quad 11$

Affectif 12

Motivation 4

Personne 2

nes, tâches et stratégies. On constate alors un équilibre entre ces trois dimensions, les items "personnes" représentent environ $32 \%$ de l'ensemble, "tâches", 37\% et "stratégies", 31\%. On sait par ailleurs que 28 items de type cognitif décrivent aussi le "comment et pourquoi" des activités, ce qui constitue aussi des connaissances de type métacognitif. On pourrait donc réajuster ainsi les items représentant ces trois aspects: "personnes", 29\%; "tâches", 34\% et "stratégies", $37 \%$. 
TABLEAU 6

Nombre d'items portant sur les sous-catégories de connaissances de type métacognitif (PSY 2040)

\begin{tabular}{ll}
\hline Sous-Catégorie & Nombre \\
\hline d'ltems \\
\hline Personnes (Total) & 89 \\
Connaissances & 59 \\
Évaluation & $\mathbf{3 0 7}$ \\
Tâches (Total) & 103 \\
Connaissances & 31 \\
Planification & $9(8)$ \\
Régulation & $\mathbf{1 4}(\mathbf{9 )}$ \\
Évaluation & $49(10)$ \\
Stratégies (Total) & 87 \\
Connaissances & $\mathbf{3 5}$ \\
Planification & 1 \\
Évaluation & 51 \\
\hline
\end{tabular}

\section{CONCLUSION ET DISCUSSION}

Certains auteurs prétendent que l'enseignement à distance favorise l'autonomie de l'étudiant. En effet, le mode d'apprentissage privilégié oblige l'individu à prendre en charge certaines dimensions (le temps et l'environnement) de son apprentissage en partie assumées par le professeur ou l'environnement dans un système d'enseignement sur campus. Nous croyons que même pour les aspects définis par le concepteur du cours, l'étudiant peut assumer un certain degré de prise en charge et de gestion de son apprentissage. C'est le cas pour les objectifs, les stratégies et même les contenus.

Nous avons défini l'autonomie par le degré de gestion qu'assume un étudiant de la situation d'apprentissage dans laquelle il est engagé. En utilisant la notion de métacognition, on décrit alors la gestion de son activité cognitive comme la planification, la régulation et l'évaluation des divers aspects de la situation d'apprentissage. Pour arriver à cette gestion, il faut, comme le soulignent plusieurs auteurs (Gordon, 1985; Kitchener, 1983; Paris et Jacobs, 1984; Sanacore, 1984) que l'étudiant possède des connaissances qui portent sur les personnes, les taches et les stratégies. Nous admettons que l'enseignement à distance exige de l'autonomie sur les plans temps et environnement. Par ailleurs, nous considérons que ce type d'enseignement peut permettre à l'étudiant d'exercer son autonomie ou d'en favoriser le développement par une gestion plus complète de son apprentissage. 
La plupart des individus n'ont pas nécessairement appris comment "être autonome" en situation d'apprentissage ou comment gérer leur apprentissage. Il nous apparait donc important de leur offrir des moyens de l'apprendre. En enseignement à distance, les cours proposent généralement aux étudiants des activités d'apprentissage de type cognitif. De la même façon, il peut être intéressant de leur suggérer des activités de type métacognitif pour qu'ils puissent gérer leur apprentissage et aussi apprendre à le faire.

Nous avons analysé les activités d'apprentissage d'un cours contenant des items de type métacognitif suggérées par le concepteur pour aider les eetudiants à prendre en charge leur apprentissage. Nous avons constaté que les activités analysées peuvent favoriser l'autonomie de deux façons: par des connaissances et par des activités de gestion de son apprentissage.

1) Des connaissances: Le concepteur fournit, avec ses activités, des descriptions contenant des définitions, des objectifs et/ou des procédures qui constituent des informations sur les stratégies et qui correspondent à des connaissances de type métacognitif (Bauman et Ballard, 1987; Flavell, 1981). Le concepteur propose aussi des acti-vités qui permettent à l'étudiant d'identifier et de nommer plusieurs caractéristiques de la situation d'apprentissage portant sur les personnes, les tâches et les stratégies. Toutes ces connaissances, de type métacognitif, favorisent la régulation et caractérisent souvent les sujets les plus performants (Baker et Brown, 1984a et 1984b; Gambrell et Heathington, 1981; Horowitz, 1985; Kurtz et Borkowski, 1984; Sanacore, 1984; Schneider, Borkowski, Kurtz et Kerwin, à paraître; Surgent, 1985).

2) Des activités de gestion: Les activités proposées fournissent à l'étudiant des instruments de planification, de régulation et d'évaluation en rapport avec différents aspects de sa situation d'apprentissage. Ce sont des activités qui correspondent à la composante "exécutive" du processus de prise en charge (Hasselbhorn et Korkel, à paraître) et qui assurent à l'apprenant un bon déroulement de son apprentissage (Baker et Brown, 1984b). Ce sont aussi, par ailleurs, des stratégies que les sujets, même adultes, ont de difficultés à maîtriser (Baker et Brown, 1984a; Maki et Berry, 1984; Surgent, 1985; Waern et Akwall, 1981).

Il nous semble donc évident que le type d'activités proposées dans ce cours peut non seulement favoriser l'autonomie de l'étudiant par la prise en charge de sa situation d'apprentissage mais aussi lui permettre d'augmenter ses 
connaissances et de développer des stratégies normalement reliées à la prise en charge et à l'autonomie. Ces connaissances et ces stratégies sont habituellement transférables (Brown et al., 1984) à une nouvelle situation de telle sorte que l'étudiant peut augmenter sa compétence à gérer ses apprentissages.

$\mathrm{Si}$, d'un point de vue théorique, la définition que nous proposons et les conclusions que nous dégageons de l'analyse d'un cours paraissent pertinentes et prometteuses en termes d'autonomie des étudiants, plusieurs questions méritent d'être retenues dans l'élaboration de recherches expérimentales et justifient une évaluation sérieuse du cours analysé.

1) Quel est l'impact réel des activités métacognitives sur les processus cognitifs d'acquisition d'informations? Si nous commençons maintenant à mieux connaître les processus de mémorisation sous-jacents à l'apprentissage (Fortin et Rousseau, 1988), nous ignorons actuellement à peu près complètement comment la prise en charge de son apprentissage peut influencer les activités d'encodage, de maintien ou de récuperation des informations en mémoire. Aussi, nous ne savons pas comment cette gestion peut influencer les processus de compréhension en termes de hiérarchisation des informations, de construction du sens global d'un message ou d'élaboration d'inférences (Denhière, 1984; Deschênes, 1988).

2) Quelle est la réaction des étudiants à ce type d'activités dans un cours? On sait que souvent, les étudiants ne réalisent pas les activités de type cognitif proposées par le concepteur ou ne les complètent pas comme le concepteur l'a demandé (Landry, 1987). Que se passera-t-il pour les activités de type métacognitif? Il est accepté par plusieurs auteurs (Armbruster et Brown, 1984;

Baker et Brown, 1984a et 1984b; Glenberg, Wildinton et Epstein, 1982; Langer et Imber, 1979) que certains processus métacognitifs (d'évaluation en particulier) se déroulent souvent de façon inconsciente à moins que ne surgissent des difficultés, on peut alors se demander comment les étudiants réagiront au fait de prendre conscience de ces processus en cours d'apprentissage.

3) Est-ce que ces activités peuvent être des distracteurs en regard des processus cognitifs à mettre en oeuvre pour acquérir les connaissances visées par le cours (Fisher et Mandl, 1988)? Ne vaudrait-il pas mieux présenter la démarche métacognitive dans un cours particulier sans contenu autre que celui portant sur les aspects spécifiques de la gestion et de la prise en charge de son activité d'apprentissage? A quel moment, en termes de nombre d'activités ou d'endroits où elles sont placées, ces activités peuvent-elles devenir nuisibles à l'apprentissage? Il y a peu de réponses à ces questions actuellement. Baker et Brown (1984b) croient, malgré tout, que l'apprentissage de stratégies métacognitives doit se réaliser avec des contenus réels à acquérir. Il n’y 
a cependant pas de recherche pertinente à ce sujet, à l'exception des travaux de Brown et de ses collaboratrices qui portent sur la compréhension en lecture de textes courts avec des enfanta en difficulté. Quant à l'aspect quantitatif, on peut croire, intuitivement, qu'une activité métacognitive trop importante pourrait effectivement nuire à la mise en oeuvre des processus cognitifs et ainsi ralentir l'apprentissage, mais nous ne connaissons pas de recherches confirmant cette intuition.

4) Une autre question porte sur le genre de feedback à fournir à l'étudiant. Selon Lefebvre-Pinard et Pinard (1984) l'individu construit ses connaissances de type métacognitif par le feedback qu'il reçoit ou se donne lui-même lors de la réalisation d'une tâche cognitive. Par exemple, devrait-on fournir des tests auto-diagnostics permettant à l'étudiant de se situer à partir des données recueillies auprès d'une population dont il ferait partie? Les questions relatives au feedback posent un certain nombre de problèmesconcernant son contenu, sa formulation et la façon dont les étudiants le reçoivent. Fisher et Mandl (1988) ont observé que certains sujets interprètent de façon négative un feedback relativement neutre de type informatif.

Il y a dans ces questions un vaste domaine de recherches. L'autonomie s'appuie souvent sur des croyances dont la mise en pratique a conduit à bien des déceptions et des échecs (Hostler, 1986). Nous croyons maintenant avoir en mains, avec la notion de métacognition, un outil conceptuel nous permettant de progresser, tant dans nos pratiques pédagogiques que dans nos recherches.

\section{RÉFÉRENCES}

Armbruster, B.B. et Brown, A.L. (1984). Learning from reading: the role of metacognition. In R.C. Anderson, J. Osborn et R.J. Tierney (Eds), Learning to read in American schools: basal readers and content texts. Hillsdale, NJ Erlbaum.

Baker, L. et Brown, A.L. (1984a). Cognitive monitoring in reading. In J. Flood (Ed.), Understanding reading comprehension. Newark, NJ: IRA.

Baker, L. et Brown, A.L. (1984b). Metacognitive skills and reading. In D. Pearson (Ed.), Handbook of reuding research. New York, NY: Longmans.

Baufmann, J.F. et Ballard, P.Q. (1987). A two step mode1 for promoting independence in comprehension. Journal of Reading, 30 (7), 608-612.

Brown, A.L., Palincsar, A.S., et Armbruster, B.B. (1984). Instructing comprehension fostering activities in interactive learning situations. In $\mathrm{H}$. Mandl, L.L. Stein et T. Trabasso (Eds), Learning and comprehension of text. Hillsdale, NJ: Erlbaum.

Davey, B. (1986). Using text book activity guides to help students learn from textbooks. Journal of Reading, 29, 489-494. 
Denhière, G. (1984). II était une fois...compréhension et souvenir de récits. Lilles: PUL.

Deschênes, A.-J. (1988). La compréhension et la production de textes. Québec: Presses de l'université du Québec, Monographies de psychologie.

Deschênes, A.-J. (1989, juin). Activités d'apprentissage et enseignement à distance. Communication présentée au Congrès de l'ACEEA/CASAE, Québec.

Deschênes, A.-J., Bourdages, L., Lebel, C., et Michaud, B. (1988). A propos des activités d'apprentissage pour faciliter l'acquisition de connaissances à l'aide de documents écrits. Revue de I'enseignement à distance, 3 (2), 97114.

Deschenes, A.-J., Bourdages, L., Michaud, B., et Lebel, C. (à paraître). A propos de la nature des activités d'apprentissage dans l'acquisition de connaissances à l'aide de documents écrits conçus pour l'enseignement à distance. Revue québécoise de psychologie.

Deschênes, A.-J., Bourdages, L., Michaud, B., et Lebel, C. (1989, novembre). Activités d'apprentissage et enseignement à distance auprès des adultes. Communication présentée au Congres des Sciences de l'éducation de langue française du Canada. Sherbrooke, PQ.

Deschênes, A.-J., et collaborateurs (1989). Vie quotidienne et santé mentale. Télé-Université, $\mathrm{PQ}$.

Deschênes, A.-J. (1989, juin). A utonomie et enseignement à distance. Communication présentée au Congrès de l'ACEEA, $\mathrm{PQ}$.

Fisher, P.M., et Mandl, H. (1988). Knowledge acquisition by computerized audiovisual feedback. Journal européen de psychologie de l'éducation, $3(2), 217-234$.

Flavell, J.H. (1981). Cognitive monitoring. In W.P. Dickson (Ed.), Children's oral communication skills. New York, NY: Academic Press.

Flavell, J.H. (1985). Développement métacognitif. Dans J. Bideaud et M. Richelle (eds), Psychologie développementale, problèmes et réalités (pp. 2941). Bruxelles: Pierre Mardaga.

Fortin, C., et Rousseau, R. (1989). Psychologie cognitive. Québec: Presses de l'Université du Québec.

Gambrell, L.B., et Heathington, B.S. (1981). Adult disabled reader's metacognitive awareness about reading tasks and strategies. Journal of Reading Behavior, XIII, 215-222.

Garrison, D.R., et Baynton, M. (1987). Beyond independence in distance education: the concept of control. American Journal of Distance Education, 1(3), 3-15.

Glenberg, A.M., Wildinton, A.C., et Epstein, W. (1982). The illusion of knowing: failure in the self-assessment of comprehension. Memory and Cognition, 10, 597-602.

Gordon, C.J. (1985). Modeling inference awareness across curriculum. Journal of Reading, 28, 444-447. 
Hasselhorn, M., et Korkel, J. (à paraître). Metacognitive versus traditional reading instruction: The mediating role of domain-specific knowledge on children's text-processing.

Henri, F., et Kaye, A. (1985). Le savoir à domicile, pédagogie et problématique de la formation à distance. Québec: P.U.Q.

Henri, F. et Lescop, J.-Y. (1988, octobre). La communication assistée par ordinateur en formation à distance: Vers une stratégie d'implantation de l'innovation. Télé-Université.

Holmberg, B. (1974). Distance education. Malmo, Sweden: Shorts Handbook, Hermods.

Horowitz, R. (1985). Text patterns: Part 1. Journal of Reading, 28, 448-454.

Hostler, J. (1986). Student autonomy in adult classes. , University of Manchester: Manchester Monographs.

Kitchener, K.S. (1983). Cognition, metacognition, and epistemic cognition. Human Developpement, 26, 222-232.

Kurtz,B.E. (à paraître) Cognitive and metacognitive aspects of text processing. In G. Denhière et J.P. Rossi (Eds), Text and text processing. Amsterdam: North Holland.

Kurtz, B.E., et Borkowski, J.G. (1984). Children's metacognition: Exploring relation among knowledge, process, and motivational variables. Journal of Experimental Child Psychology, 37, 335-354.

Landry, F. (1987). Revue de littérature sur le role des activités d'apprentissage dans l'enseignement à distance. Document non publié, Québec: Téléuniversité.

Langer, J.A. (1986). Learning through writing: Study skills in the content areas. Journal of Reading, 29,400-406.

Langer, E. J., et Imber, L. G. (1980). When practice makes imperfect: debilitating effects of over-learning. ornal of Personality and Social Psychology, 37, 2014-2024.

Lefebvre-Pinar, M., et Pinard, A. (1984). Taking charge of one's cognitive activity: Amoderator of compentence. In E. Neimark (Ed,), Moderators of competence. Hillsdale, NJ: Erlbaum.

Maki, R.H., et Berry, S. (1984). Metacomprehension of text material. Journal of Experimental Psychology: Learning, Memory and Cognition, 10, 663679.

Paris, S.G., et Jacobs, J.E. (1984). The benefits of informed instruction for children's reading awareness and comprehensive skills. Child Development, 55, 2083-2093.

Pinard, A. (1987). Cognition et métacognition: les recherches sur le développement de l'intelligence. Interface, 8(6), 18-21.

Pinard, A., Bibeau, M., et Lefebvre-Pinad, M. (1985). Le savoir métacognitif portant sur la compréhension: Comparaison entre adultes analphabètes et adultes alphabétisée. J. Bideaud et M. Richelle (Eds), Psychologie développementale, problémes et réalités ( $\mathrm{pp}$. 43-59). Bruxelles: Pierre Mardaga.

Pressley, M., Borkowski, J.G., et O’Sullivan, J. (1984). Memory strategy 
instruction is made of this: Metamemory and durable strategy use. Educational Psychologist, 19, 94- 107.

Botaeche, A.B. de (1987, August).The influence of an instructional design upon learning of distance education students in Venezuela. Zentrales Institutf ur Fernstudienforschung, Hagen.

Sanacore, J. (1984). Metacognition and the improvement of reading: Some important links. Journal of Reading, 27, 706-712.

Schneider, W., Borkowski, J.G., Kurtz, B.E. et Kerwin, K. (à paraître). Metamemory and motivation: a comparison of strategy use and performance in German and American children. Journal of Cross-Cultural Psychology.

Steward, O., et Tei, E. (1983). Some implications of metacognition for reading instruction. Journal of Reading, 26, 37-43.

Surgent, E.A. (1985). Memory and memory monitoring: Levels of processing, idea unit level, and text organization in the retention of prose. The Psychological Record, 35, 251-268.

Thomas, J.W., et Bohwer, W.D. Jr. (1986). Academic studying: The role of learning strategies. Educational Psychologist, 21(1\&2), 19-41.

Tremblay, N.A. (1986). Apprendre en situation d'autodidmie. Montréal: Les presses de l'université de Montreal.

Waern, Y., et Askwall, S. (1981). On some sources of metacomprehension.

Scandinavian Journal of Psychology, 22, 17-25

\section{NOTES}

1. Ce texte a fait l'objet dune communication lors du Congrès de l'ACFAS en mai 1989 à Montréal.

2. Voir D-chênes, Bourdages, Lebel et Michaud 1989 pour un résumé de ces travaux.

3. Tremblay (1986) définit l'autodidaxie comme "le phénomène par lequel un individu décide d'apprendre par lui-même"; ce terme est utilisé pour décrire la situation où l'apprenant assume lui-même "l'ensemble des fonctions d'enseignement (didactique)" (p. 11).

4. Ce projet est présenté dans Deschênes, Bourdages, Lebel et Michaud, 1989.

5. On peut obtenir une copie du document de travail décrivant ces catégories et sous-catégories en la demandant à l'un ou l'autres des auteurs.

6. La catégorie connaissances renvoie à des items qui demandent aux étudiants d'identifier, de nommer ou de prendre conscience des connaissances portant sur les personnes, les tâches ou les stratégies.

7. Comprend les items Evaluation: connaissances, affectif, motivation et personne.

8. Comprend les items Planification: objectifs et tâches.

9. Comprend les items Régulation: objectifs et temps.

10. Comprend les items Evaluation: objectifs, tâches et temps. 


\section{AUTEURS}

André-Jacques Deschênes est un professeur à la Télé-université, 2635. boul. Hochelaga, 7è étage, Sainte-Foy, Québec GlV 4V9.

Louise Bourdages est une professeur à la Télé-université

Céline Lebel est une professionnelle pédagogique à la Télé-université

Bernard Michaud est un professionnel pédagogique à la Télé-univenité 
106 CJEC SUMMER 1990 


\title{
Intelligent Tutoring Systems: A Review for Beginners
}

\author{
Peter Holt \\ Peter Wood
}

\begin{abstract}
This paper presents the genesis of the use of artiflcial intelligence (AI) in education. It introduces the concept of an intelligent tutoring system (ITS) and outllnes a typical architecture while differentiating IIS's from conventional Computer Assisted Leaming (CAL). It outlines recent directlons in this field and describes the inputs of various disciplinary areas (Psychology, Education, Cognitive Science, and Artificial Intelligence) that continue to contribute to ITS development. It reviews the potential benefits of ITS's for education and potential issues in implementing them in a large scale way. Finally, the authors suggest areas for research and application development for IIS's (The paper includes a select bibliography.)
\end{abstract}

\section{INTELLIGENT TUTORING SYSTEMS AND DISTANCE EDUCATION}

\section{Introduction}

The role of Artificial Intelligence (AI) in education has been of increasing interest to researchers in recent years. However, many of the publications which deal with this topic have been too technical for a general audience in the educational field. More general publications have contained too little depth to be of use to educator who wish to become involved in applications of AI in education. This paper introduces AI techniques to various professionals in the field of education, such as subject matter experts, educational technologists, instructional designers, and management. It assumes some basic computer literacy but no real familiarity with artificial intelligence or cognitive psychology. It is intended that after reading this paper, the readers will be in a position to begin serious investigation of how ITS theory and practice can be applied in their area of expertise. 


\section{THE BASICS OF INTELLIGENT TUTORING SYSTEMS}

\section{Artificial Intelligence and Knowledge Representation}

A major research focus of artificial intelligence (AI) is to develop heuristics and algorithms that will allow computers to perform tasks that seem to depend upon human intelligence. Such research includes pattern recognition, general problem solving, game playing, and problem solving in specific narrow domains, Attempts at general problem solving programs have not been highly successful. This failure has been attributed to large degree to the lack of a representation of knowledge about the real world in these programs (Minsky, 1986). For instance, to solve medical problems by computer, the machine should possess specific knowledge about the medical domain and diagnostic techniques as well as general problem solving capabilities. It has been conceded that representing the type of general knowledge that a human being has about the real world is an intractable task for computing technology, at least for the immediate future. Research in the last fifteen years has focused on restricted domains of knowledge-limited enough that some representation by a computer is feasible (e.g., in the medical domain, the knowledge necessary for diagnosing the bacterial agent in infections and prescribing the appropriate antibiotic). This research has resulted in the concept of an knowledge based system that performs at an expert level for a restricted domain. It is generally conceded that these "expert" systems are best developed for domains of expertise involvingrestricted procedural knowledge- generally of an heuristic rather than algorithmic nature (Waterman, 1986).

If performance is the major concern, procedures that are algorithmic in nature can generally be more efficiently executed in traditional computer pro grams. Expert systems generally have at least two components: a knowledge base and an inference engine. In the expert systems knowledge base the knowledge of domain experts is represented in an appropriate data structure. Types of representations include production rules of the form 'IF $\mathrm{X}$ is true, then do $\mathrm{Y}$ " and frames. A frame is a data structure representing an object or situation and holding"slots"which contain values for specific attributes of that object. Slots may also contain actions (procedural attachments) to be performed in specific situations. Most frame base systems are hierarchical and include the concept of inheritance - frames lower in the hierarchy inherit default values for common slots from their ancestor frames higher in the hierarchy For more detail on the such matters the reader should refer to a introductory text on AI (e.g., Charniak \& McDermott, 1984).

The inference engine module of expert system makes inferences based on the production rules and other knowledge representations in the knowledge base(s). Commonly used inference methods include backwards chaining, forward chaining, and reasoning with uncertainty. Backward chaining is "an inferencing strategy which involves working back from a conclusion or goal to see if the conditions which would make it true are satisfied" (Slatter, 1987). Also termed "inductive reasoning;" it is particularly useful in domains requir- 
ing diagnostic expertise. Forward chaining is an inferencing strategy which builds up from the available data about a problem to deduce conclusions" (Slatter, 1987). It is used in such situations as defining configurations of computer systems where the final outcome is not specified in advance (deductive reasoning). Reasoning with uncertainty is a method of reasoning when "facts" are less than one hundred percent certain. It may be based on one of several methods for evaluating assertions that have a certainty or confidence factor of less than one hundred percent(e.g., "if it is cloudy there is a fifty percent chance of rain" or "if it is foggy there is a ten percent chance of rain"). Ways of combining weights (cloudy and foggy) include standard Bayesian statistics and domain specific algorithms.

Most of the original systems were coded in the LISP or PROLOG languages. Both are good for manipulating symbols which is a prerequisite for these types of systems. Prolog also has built in logical inference capabilities. Newer commercial expert system tools often include multiple ways of representing knowledge and inferencing. Such systems are referred to as "expert systems shells" in that the programmed infrastructure is in place and domain knowledge is simply added to the shell. Shells are not applicable in all domain areas as the inference process and system design are not always domain independent. Even where shells are applicable, systems development is still not trivial. One cannot overemphasize the time that is usually involved in the complex "knowledge engineering" process of obtaining knowledge from experts in a form that is amenable to representation in typical knowledge base data structures (Waterman, 1986). There have been attempts at automating this process but these are mainly applicable for very simple systems.

Expert systems have been successfully applied in many areas of expertise (e.g., chemistry, computing, geology, law, and medicine). MYCIN (Shoreliff, 1977) was one of the first expert systems; it diagnosed bacterial infections and recommended appropriate doses of specific antibiotics. Although it was an early system, it inspired much of the research into the potential use of such systems in education. Researchers reasoned that if the medical expertise necessary to solve problems in a domain could be represented in a computer, this representation could form the basis for a tutorial program for teaching such expertise.

\section{Education and Artificial Intelligence}

Researchers in the field of ITS's apply artificial intelligence techniques, such as the knowledge representation and inferencing in expert systems, to computer based education and training. These techniques allow the development of computerized learning systems that are more adaptive to the students needs than are systems based on more standard computer programming techniques. One of the earliest systems developed in the late 70's was based on the MYCIN system. This system, called GUIDON (Clancey, 1983), used the expertise represented in MYCIN as a basis for instruction. It had a number of problems such as ineffective tutorial strategies but spurred further research 
into the application of artificial intelligence techniques to education (Wenger, 1987).

GUIDON and other prototypes were developed through the late 70's and early 80's but the number of functioning ITS's remained very small, as development was limited by the large computational demands of such systems. The single textbook (Sleeman \& Brown, 1982) written in the field until 1987 indicates the level of activity. However, in recent years general acceptance of computing technology, efforts to increase cost-effectiveness through automation, a desire to connect education to industry more directly, and the improved cost-performance of hardware have made ITS's more feasible and research in the ITS area has expanded rapidly. This expansion is manifested by the several texts published on the ITS field since 1987 and a biennial international conference established in 1987 concerned with ITS design and development, There is now a journal (Artificial Intelligence and Education) dedicated to this area as well as frequent articles in other journals.

\section{A TYPICAL SYSTEM}

There has evolved a generally accepted architecture of an ITS that has endured with little change until quite recently (Self, 1989). This typical ITS (Burns \& Capps, 1988) includes four modules: the expert module (a representation of the subject area knowledge that the student is to learn), a student model module, a tutorial module, and the student-machine interface module. The interaction of these modules controls the students instruction or learning environment. Along with this typical architecture there are some general software languages/tools and typical hardware environments which are used for development and delivery.

\section{Expert Module}

The expert knowledge is generally procedural, that is, consisting of a set of actions to be performed given the prerequisite conditions amenable to rep resentation in "if.. . then.. ." rules. For example, in GUIDON the expertise is a body of rules for diagnosing bacterial infections and prescribing antibiotics. Very few systems involve declarative knowledge (e.g., knowledge of the form 'X is a Y," or "B has a C"). One example of a system representing declarative knowledge is SCHOLAR (Carbonell, 1970) which represents geographic knowledge in a semantic network. In such a network knowledge is written as a set of "nodes," representing concepts, connected by "links," representing relationships between the concepts; e.g. concepts " $x$ " and "variable" can be linked by the relationship "is-a." Other systems use combinations of rules and frames. Expert systems have focussed on areas of heuristic reasoning because often algorithmic reasoning can be represented more efficiently in more traditional computer algorithms. However, there is no reason that the expert module of an ITS could not represent algorithmic reasoning of an expert. In 
the expert module of an ITS, it is the articulation of the expert's knowledge in a form amenable to learning that is important, and not concern with the speed of execution in automating the expert's performance.

As with expert systems in general, there are a number of stages in implementing an expert module. First, one must define the knowledge at the expert level, This involves time consuming interviews with experts. A second stage is determining how best to represent this knowledge in the computer. A third stage is the often arduous implementation. Designing and implementing the expert module has all the tasks associated with developing an expert system (see for example, Walters \& Nielsen, 1988) plus the constraints and complexities imposed by the interaction with other modules.

\section{Student Model Module}

There are various approaches to representing the state of the student's knowledge in such a way as to aid in diagnosis of student problems and in remediation. A comprehensive student model would include all the student's prior learning that might be applied to the current task, the student's progress within the system and the student's learning style, as well as other types of student related information. Implementing a comprehensive model is a such formidable task that Self (1988) questions whether it is feasible or necessary, and other researchers significantly limit the scope of the student model (Elsom-Cook, 1988). Many systems attempt to model the student only in relation to the knowledge represented in the expert module. A model based on such a comparison is called an "overlay" model (Carr \& Goldstein, 1977). The student's knowledge is compared to that in the expert module and the differences comprise what the student must learn. GUIDON represented medical students as an overlay of the rules in the domain module. Thus instruction was be aimed at those rules that the student did not know. An elaboration of the overlay model uses a "genetic graph," a variant of the "semantic network" method, which contains assumptions about the order in which the student develops various aspects of expertise. The student's knowledge is described in terms of the nodes of the graph, and his learningbehaviour in terms of the edges. The student's progress is shown by the paths through the graph (see Wasson \& Jones, 1985).

Even more ambitious systems might attempt to implement the student model as a program which can be executed to simulate the student's behaviour. Such a simulation could be used to validate the model and to generate alternative models.

The major criticism of the overlay model is that students do not simply lack concepts or rules, they also have incorrect rules called "mal-rules" or "bugs" (Brown \& Burton, 1978). These are misconceptions or misunderstandings of the domain that lead to incorrect answers to problems. help diagnose and assist in remediation, an addition to the student module referred to as the "bug library' is incorporated into the system. In order to diagnose errors, this module must be able to produce the errors generated by these misconceptions 
or this specific error must be explicitly represented in the library. The best example of such a diagnostic module is a library of faulty procedures used by students in arithmetic subtraction (Brown \& Burton, 1978) which produces many of the errors commonly made by students learning the process of subtraction. While this system led to much research including a "repair" theory of how bugs are generated (VanLehn, 1982), it has not been an unqualified success. Problems with this approach include differentiating random casual slips from instances of "buggy" rules and diagnosing higher order interactions between different bugs.

Representation issues for the comprehensive student model module are a superset of those for the expert module. As well as representing the student's correct domain knowledge it may also represent mal-rules and be able to reflect learning induced changes in both types of these representations.

\section{Tutor Module}

ITS research is concerned with defining a tutorial module which will use theoptimalstrategiesandtactics for instructingthestudent. This "tutor" must take into account the target subject matter expertise and the student's current level of knowledge. Different approaches might be more appropriate for different subject matters and levels of expertise. A coaching method using hints and examples combined with exploration of simulations might be better for some physics topics, whereas a very guided tutorial with student exercises might be best for instructing LISP programming. An example of an approach used by an ITS for tutoring the LISP programming language is to define an optimal solution path and guide the student along the path, minimizing deviations from that path (Reiser, Anderson, \& Farrell, 1985). Much of the apparent "intelligence" in an ITS has to do with how the tutor module uses the knowledge represented in the student module and the expert module in interacting with the system. Knowledge representation could be in terms of frames (e.g., representing particular student states) and rules (e.g., in situation A take action B).

\section{Student-Machine Interface}

This module handles the interface between the student and computer (Miller, 1988). As such it is not unique to an ITS but is a critical component of any successful system. An interface might becommand driven, menu driven or use objects which are directly manipulated as in a "mouse"controlled interface. The design and implementation of an effective interface is a complex task in any situation (Card, Moran, Newell, 1983).

\section{Interaction of M odules}

These four modules generate and control the interaction of the ITS with the student. The interaction of the student with the system is through the interface module; the knowledge that is to be learned is in the expert module, the state of the student's knowledge is in the student module, and the method of 
instruction used is in the tutorial module in terms of computer assisted learning $(\mathrm{CAL})$, this is analogous to the computer generating the programs in response to the student's behavior, instead of all the programs being determined prior to any interaction with the student. The interaction of the ITS and the student is shaped dynamically by the knowledge represented in the four modules. The student model changes with the interaction and in the prototypical ITS architecture is particularly important in determining the ITS's tutorial tactics at any point in time.

\section{Software Languages/ Tools and Hardware Environments}

Most systems have been developed in LISP or PROLOG, some in other AI oriented languages such as LOOPS, and OPS5, some in more general object oriented languages such as SMALLTALK and $\mathrm{C}++$, and some even in $\mathrm{C}$. As with expert systems there are shells for ITS development such as DOMINIE (Elsom-Cook \& Spensley, 1988) but they are research or prototype systems and have very restricted domains.

Development hardware originally consisted of minicomputers (such as VAX 780) or special LISP processing machines. However, with the rapid growth of hardware capabilities more work has been done on supermicros rated at several MIPs such as SUN3's and SUN4's and even INTEL 80386 machines. Generally for development, hardware requirements include over one hundred megabytes of disk storage and several megabytes of RAM. Some systems have been targeted for delivery on smaller machines such as IBM PC compatibles or Macintosh computers (e.g., Quigley, 1989) but these are a very small subset of the total number of systems developed.

\section{Intelligent Tutoring Systems and Computer Assisted Learning}

Park, Perez, and Siedel (1987) presented many dimensions which discriminate between ITS and CAL technology in the early 80s. The three most relevant dimensions of discrimination are the methods of structuring domain knowledge, the process of presenting the knowledge (or the tutorial strategy), and the modelling of the student. ITS's manipulate knowledge using representations by rules and/or frames as contained in expert systems. The knowledge of the domain is represented explicitly outside the controlling program or interpreter. In CAL there is no attempt to represent the knowledge explicitly. Instead, there is a pre-specified series of templates which present subsets of the subject matter in an order determined beforehand by the programmer and the instructional design. Thus in CAL the tutorial strategy is built in on a stepby-step basis by the designer and programmer, whereas in ITS's the designer attempts to give the system the rules and tutorial expertise with which it can react dynamically to the student's actions. Finally, in CAL the student is modelled by quantitative scores or binary judgements of student responses. In an ITS as previously explained, the student is modelled by an overlay of the domain expertise and perhaps by a library of "bugs."

In summary, properly designed ITS's should be more flexible and 
responsive than CAL systems. However, it is not yet clear that ITS technology is the best solution to instructional problems in all areas. In some domains (e.g., remedial grammar) simple drill and practice may be the best strategy. Furthermore, few if any ITS's have been demonstrated to be successful for other than procedurally oriented tasks (Park et al., 1987; Anderson, 1988).

\section{RESEARCH FOUNDATIONS OF \\ INTELLIGENT TUTORING SYSTEMS}

The ITS area is interdisciplinary. Basic and applied research in education, psychology, cognitivescience, and artificial intelligence have contributed to the emerging ITS technology and will continue to play a large role in its maturation As the ITS field develops, other areas such as linguistics (e.g., natural language processing) and anthropology (e.g., the cultural aspects of learning) should actively contribute to the field, however, their direct contributions to date have been very limited.

\section{Education}

lb a large extent development of the ITS field has been driven by AI technology rather than by educational needs or research findings. Very little of the knowledge gained from research into "unintelligent"ComputerAssisted Learning has been incorporated into ITS's. These have focused on the representation of domain, tutorial, and student model knowledge with little consideration of factors such as reinforcement and feedback that have been research issues in CAL.

Within the field of instructional design much research has been done on how to organize instructional materials and the learning process to optimize student learning ( e.g., Gagne, Briggs, \& Wager, 1988 is an example of one approach). However, this large body of research seems to have had little impact on the ITS field (Park, Perez, \& Siedel, 1987). According to Wenger (1987), most early systems focussed mainly on intelligent responses to the students actions at a local level. Wenger characterizes these systems as "opportunistic" as opposed to plan-based tutoring architectures which are more in the tradition of much of the instructional design research (Gagne et al, 1988). More recently work by researchers such as Brecht, McCalla, Greer, and Jones (1989), Winne (1988), Derry, Hawkes, and Ziegler (1988) and Woolf (1988) have addressed this issue of using "intelligence" in planning tutorial interactions and curriculum planning.

There is a tradition in education of focussing upon learning environments where the student learns rather than is taught. It has had an large influence in earlier computer based learning systems such as the "microworld" learning systems developed by Papert and his co-workers (Papert, 1981). In these systems learners can create a problem domain and explore it at leisure under self-determined conditions and "construct" their own solutions. In contrast, 
instead of providing the student with a learning environment, most of the original ITS's are based on a philosophy of representing the expert's knowledge so that it could then be transmitted to students. Recently researchers in the ITS field have acknowledged the need to develop ITS's more in line with the learning environment approach or "microworld" approach (Brown, 1989; Cumming \& Self, 1989; , Pea \& Soloway, 1988; Self, 1989). Ultimately, while ITS has much to contribute to educational theory development, the ITS field must keep pace with other educational research to remain relevant. At a much more mundane but still critical level there must be more educational evaluation of working systems (Littman \& Soloway, 1988) and meta-evaluation of the ITS approach to education.

\section{Cognitive Science and Psychology}

The series of versions of ITS systems relating to subtraction (BUGGY, DEBUGGY, IDEBUGGY see Wenger, 1987 for a review) developed by Brown, Burton, and their collaborators has been very influential in the ITS field. These systems assumed that when students learned the basic skills of subtraction many of their errors were due to the use of faulty or incorrect operating rules (e.g., 0 - any number = that number). The goal of the system was to diagnose and remediate these 'bugs'. The systems have had limited success but generated a great deal of useful research. One interesting research finding was the development of the "Repair" theory of how students acquire these bugs (VanLehn, 1982).

A “mental model" (Norman, 1983) refers to a person's internal representation of things with which they interact which provide predictive and explanatory power for understanding the interactions. The term "mental model" is most commonly used in regard to physical devices and systems. The basic concept of a user (or student) having an internal representation with some isomorphic relationship to an external device or subject matter is inherent in the ITS representing the student's knowledge of the area (Kieras, 1988). Research in this area should continue to play a large role in the ITS field.

The research related to J. Anderson's ACT model of human cognition (Anderson, 1983) has contributed directly and significantly to Anderson's ITS's. This theory models human cognition as production systems. Expertise in an area such as LISP programming is then represented as a set of production rules. These rules can be executed to simulate human competence. In the LISP Tutor (Beiser, Anderson, \& Farrell, 1985), the domain expertise is represented in just such a fashion and students are tutored to acquire the appropriate rules in the appropriate order.

More generally any new theory of cognition, particularly in relation to the acquisition of cognitive skills and natural language, will be relevant to the ITS field. As well as cognitive research, it is apparent that research from learning theory must be relevant to the design of feedback to the student. Also it seems that as the ITS field becomes more sophisticated, other areas of psychology will become more relevant. For example, as distributed processing and networking 
become more sophisticated, a "distributed ITS" could interface with groups of students and mediate their interactions. There may well be a a role for social psychology in planning such group learning systems.

\section{Artificial Intelligence}

Research into expert systems technology and associated knowledge engineering methodologies has been the most influential upon ITS development. The most immediate impact on the field seems likely to come from research into the area of automated knowledge acquisition,

AI research in "belief revision" (Vardi, 1988,) aimed at representing human beliefs, is very relevant to ITSs. Since human belief systems appear to be non-monotonic, that is, new information added to the system can invalidate a previously "correct" conclusion which then must be deleted or modified, it is quite a challenge to revise and maintain such systems. However, as pointed out by McCalla (1987), any sophisticated ITS will need to represent such nonmonotonic changes in the student model. Research into various types of knowledge representation such as semantic nets and frames as well as the investigation of natural language understanding remain relevant to ITS's. Another area of relevant research work is that on qualitative reasoning systems (Bobrow, 1984). In qualitative reasoning, experts work with nonquantitative models of physical and other systems. For example, a representation of current flow might include the rule that "if the voltage at $\mathrm{A}$ is higher than the voltage at B a current will flow from A to B," with no explicit quantitative representation of voltage.

Another potential development of great impact would be the production of 'shell systems" for developing ITS's. However, since the conceptual foundations, thearchitectures, and design methodologies of ITSs are in an early stage of evolution, and there may be no general purpose shells in the immediate future. In fact it may be that the representations of knowledge and tutorial strategies will become so domain specific that there will never be a general purpose, domain independent ITS shell. However, this would not preclude the development of tool boxes for the development of common elements (e.g., genetic graphs) or of shells for domains with common characteristics.

\section{Neural Networks}

The connectionist or neural network approach to perceptual and cognitive modelling (Anderson \& Rosenfeldt, 1988) is currently of great interest in psychology, cognitive science, artificial intelligence and other areas contributing to ITS development. For this reason it will be discussed in somewhat more detail than its current contributions to ITS's may justify. The connectionist approach has a long history (Rosenblatt, 1958) but remained dormant from the 60's until quite recently after a critique (Minsky \& Papert, 1969). An information-processing approach to cognition (e.g., Newell \& Simon, 1972) assumes that most human cognition can be modelled by an architecture based on Von Neumann computer architecture. This approach assumes a single, limited 
capacity, relatively complex central processor which processes symbols serially; a short term memory, a longer term memory, and some mechanism for switching attention or allocating resources. Retrieval from memory is based on a method of specifying memory addresses. All of these assumptions have been questioned at one time or another, but never with more vehemence and to such an extent as with the recent revival of connectionism (e.g., Rumelhart \& McClelland, 1986). Aconnectionist model assumes that there are a very large number of simple processing units operating in parallel on input, and that memory is distributed and content addressable. Such a model assumes the simple processing units share some number of inhibitory and excitatory connections. The basis of the model is an extremely simplified view of the behaviour of neurons (hence "neural nets"). Much of the recent revival in interest in this approach is due to the fact that these "models" can now be implemented in software and hardware. Such implementations have shown many interesting behaviours. In fact, this technology has had some remarkable early successes in pattern recognition (Gorman \& Sejnowski, 1988) and transformation (Sejnowski \& Rosenberg, 1986).

How much success the connectionist approach will have in modelling high level cognitive processes is currently the subject of intense debate in cognitive psychology and artificial intelligence Pinker \& Mehler, 1988; Rumelhart \& McClelland, 1986). Regardless of the eventual success or failure of neural net models of cognition, they do not seem directly relevant to the current or emerging generation of ITS's. Neural net models are not articulated in a easily understandable fashion and such articulation of knowledge is the underpinning of this ITS technology. It may be that in the future ITS's based on neural network models of expertise will be implemented, but they will be radically different from today's ITS's. In the shorter term the contribution of the neural net model to ITS design might be the application of their pattern recognition and generation capabilities to improve user interfaces. For instance, neural net technology could be used to provide the capability for recognizing a particular student (perhaps by visual input or input device response patterns, much as old-time Morse telegraphists knew each other's “fist" or key-operating pattern). Even more immediately, neural nets might be used to provide a classification of a student by patterns of response (Beale \& Finlay, 1989). It may also be that neural nets will provide general pattern recognizing capabilities tostudents as explicit tools in their learning environment (in the same way databases, spreadsheets, and statistical packages are tools).

\section{Human Factors}

Without a good interface, the most sophisticated inferencing systems are going to fail in a general educational setting. ITS's will have to stay abreast or ahead of advances in interfaces available in commercial applications to be successful. Human Factors is a broad interdisciplinary area within which human computer interactions are one focus. Much of the research has been at a perceptual-motor level (e.g., colour and contrasts in screens and keyboard 
layout; Card, Moran, \& Newell, 1983) but there is also considerable research into what are the user's conceptions of systems and the design of more "intelligent" user interfaces (Baecker, 1987; Miller, 1988; Norman \& Draper, 1986). Work in this area of cognitive engineering will be particularly relevant to human interface issues.

\section{ITS APPLICATIONS IN EDUCATION}

\section{The Benefits of Implementing ITS Technology}

The obvious use of ITS technology in education is in intelligent courseware. The need is greatest in areas which are not amenable to text presentation due to requirements for immediate interactive feedback or sensory input such as lab simulations or case studies. It may also be that there are areas which traditionally have not gone beyond text but this is due solely to the limitations of text and lecture media. Computer media may provide breakthroughs in these areas (e.g., one can imagine simulated battles in alternate history scenarios - for instance, what if Hitler had concentrated entirely on the Russian front at the expense of the Italy campaign?).

These systems have the potential to be more responsive to an individual learner's requirements than systems based on printed materials or conventional CAL. The explicit representation of subject matter expertise, tutorial strategies, and student models creates a system which ideally, in a limited domain, can behave as if it "understands" the students' competencies and apply the correct teaching methods without human intervention. ITS's, like CAL, allow self pacing while in general being more responsive and flexible. ITS's can also serve as guides to students exploring online information and knowledge bases.

In classroom educational settings such systems could ease the workload of teachers, thus freeing teachers' time for tutoring students on the more conceptually complex problems. They can provide education in areas where there is a shortage of human expertise. In distance education, where students often rely almost entirely on printed materials, such systems could be surrogates for certain teacher-student interactions.

Other uses of ITS's are computer managed learning and course design (Wipond \& Jones, 1988; Winne (1988), online help with computing and data communications systems (Mathews, Biswas, \& Neelakandan, 1988), and intelligent guides for knowledge and database exploration. ITS's also could act as repositories for expertise on subject matter tutorial strategies that are not easily stored in text format. As well as specific benefits associated with their

ITS's can access the general capabilities of computers (graphics, simulations, data communications, hypertext tools) that are not so well integrated into text-based materials. Finally, developing an ITS can enhance the expert's view of the domain. Investigating the best way to represent the domain and related tutorial strategies in algorithmic and heuristic form is likely to uncover new ways to think about and represent domain knowledge. 


\section{Issues in Implementing ITS Technology}

There are problems with ITS technology at a number of levels. It is a new interdisciplinary area, and communications between the various contributing disciplines need to be enhanced. Specifically, there needs to be more direct educational input to the field. More systems must be developed for evaluation and more ITS tools must be made available. There must be ongoing applied research at implementation sites. At a more practical level, there are a number of problems with implementing ITS's within any standard educational organization. Although such considerations may not seem germane to academic researchers, these types of problems may be the most difficult to resolve. It is the opinion of some veterans of CAL that the main stumbling block is not instructional efficacy but organizational issues in implementing a new instructional technology in a lecture oriented institution. (e.g., Hunka, 1988).

Zealous promotion of ITS's on their strengths of "intelligence" and flexibility combined with criticism of existing educational techniques may make educational staff see these systems as competing for their jobs and they will resist their implementation. Without enthusiastic cooperation ofstaffand a major training effort, these systems will require the creation of new positions within the institution which may compete with existing positions for funding. Such competition will create more staff resistance to this technology, Career advancement generally is based on existing structures and functions and there currently is little motivation for staff to become involved in development and implementation of these systems. Even without active resistance, ITS's may not fit well with the existing technical infrastructure for production or delivery of educational materials.

Beyond problems with staffing and organizational structure, there are cost issues. It is generally conceded that these systems take significant time to develop (Begg \& Hogg, 1987). Although it is logical to assume that costs will decrease after an initial startup, there is no doubt that to implement ITS's on any large scale will be extremely expensive. One scenario would be nationally centralized production, but this might raise other problems related to the standardization of education which runs counter to Canada's currently decentralized and pluralistic approach to educational philosophy and practice. Once developed (or purchased) there would still be implementation costs for software, hardware, and data communications. These systems are very demanding of these resources and any major implementation would require extensive upgrades in even the most computerized institutions. Even with the rapid drop of costs for hardware, these costs would be substantial.

\section{Getting Started with ITS Technology}

There will need to be simultaneous acceptance at the grass-roots, support and management levels to implement ITS's on a large scale in an educational institution. Our advice to management is to work on getting the technical infrastructure for all computing related course delivery in place. That is the 
most important step. Put a delivery system in place. It is critical for staff to have experience with the network, student workstations and simple technology (such as file transfers, editing tools, electronic mail) before implementing advanced instructional technologies. However, at the same time management should encourage staff experimentation with more advanced technologies.

For the staff who wish to experiment, there are several review papers from different perspectives that are good starting points. Woolf (1988) gives a good review of the current status of the field. Seeley Brown (1989) points out recent trends in education that developers of ITS's must take into account. Self and Cumming (1989) provide a similar perspective on what the educational strategy of ITS's should be. For more depth, the beginner should read the following texts. Wenger (1987) reviews various systems in some depth and attempts to provide a framework for conceptualizing the similarities and differences between these systems. This booksupplies a good review of the field since its beginning. A book of readings edited by Psotka (1988) pays less attention to early systems and is less oriented towards AI. Instead it looks in some detail at recent work involving ITS's in areas that must be considered by any developers of ITS's; cognitive science (mental models, problem solving), education (instructional design), AI (knowledge acquisition), and human factors (interface design). It also presents overviews of some of the more recent systems. A book of papers put together as an introduction to the area for the U.S. Armed Forces (Polson \& Richardson, 1988) takes an even more pragmatic approach and presents the closest thing to a cookbook for ITS's. It takes a close look at the standard modules of ITS's and other issues (such as evaluation) for would-be developers to consider. While it may be somewhat short on technical detail and somewhat premature in relation to the current status of ITS technology to be a real cookbook, it certainly helps present the field from a pragmatic viewpoint.

From there individuals should review the most recent proceedings from the two biennial conferences dedicated to this area. (More readings are listed in the select bibliography.)

After getting a good overview of the field, there are a myriad of potentially productive paths that an individual could follow. There is basic and applied research required in all of the areas contributing to ITS technology as well as within the area itself, giving researchers a great deal of flexibility in following the path most suited to their aptitudes, needs, and ambitions. Richardson (1988) lists a number current research and development needs and opportunities. For example, one critical research direction for education is determining how to develop successful systems requiring non-procedural knowledge (e.g., declarative knowledge and qualitative reasoning). Currently, ITS technology has not dealt to any degree with subject matter other than very procedurally defined tasks (Anderson, 1988). Another issue particularly relevant to education is how to present different viewpoints of the same domain (Moyse, 1989; Suthers, 1988; Self (1989).

Interested individuals should obtain at least one ITS with which to 
experiment. More technically oriented individuals should also experiment with one or more shells for ITS or expert systems development. Despite the rapid improvement in technology and assertions about the cost-effectiveness of ITS (Woolf, 1988b), developing these systems is still a complex process at all stages including the implementation. One very good way to appreciate this complexity is to conduct some development work. It may be possible to obtain an ITS shell from researchers in the field. However, since shells specific to ITS development are mostly in a prototype stage, readers may have to start by using commercial shells for expert systems development. Some of these shells are in the public domain or can be acquired for a relatively small sum of money (Lippert, 1987). Whether or not such a shell will be suitable for development of any module of an ITS depends upon the content and design complexity of the subject matter. It is unlikely that an entire ITS can be developed with one. Regardless, such shells are a good starting place for the novice.

\section{REFERENCES}

Anderson, J. A., \& Rosenfeld, E. (Eds.) (1988). Neurocomputing: A reader. MA: MIT Press.

Barr, A., \& Feigenbaum, E. A. (Eds.) (1982). The handbook of artificial intelligence (Vols. I-II). Los Altos, CA: William Kaufmann, Inc.

Bierman, D., Breuker, J., \& Sandberg, J. (Eds.) (1989). Artificial intelligence and education: Proceedings of the 4th International Conference on AI and Education. Amsterdam, Holland: IOS.

Boden, M. A. (1987). Artificial intelligence and natural man. (2nd ed.). New York, NY: Basic Books, Inc.

Born, R. (Ed.) (1989). Artificial Intelligence: The case against. Beckenham, UK Croom Helm.

Brown, J. S. (In Press). Towards a new epistemology for learning. In C. Fraisson \& J. Gauthiers (Eds.), Intelligent tutoring systems: At the crossroad of Al and education. Norwood, NJ: Ablex.

Chambers, J.A., \& Sprecher, J. W. (1983). Computer-assisted instruction: Its use in the classroom. Englewood Cliffs, NJ: Prentice-Hall, Inc.

Clancey, W. J. (1987). Methodology for building an intelligent tutoring system. In G. P. Kearsley (Ed.), Artificial intelligence \& instruction: Applications and methods, pp. 193-227). Reading, MA: Addison-Wesley Publishing Co.

Duchastel, P. (1988, July). Research directions for ICAI in Canada. Canadian Artificial Intelligence/Intelligence Artificiele au Canada, 16, 16-19.

Gagne, R., Briggs, L., \& Wager, W. W. (1988). Principles of instructional design (3rd ed.). New York, NY: Holt, Rinehart and Winston.

Gevarter, W. B. (1984). Artificialintelligence, expertsystems, computer vin, and natural language processing. Park Ridge, NJ: Noyes Publications.

Glass, A. L., \& Holyoak, K. J. (1986). Cognition. (2nd ed.). New York, NY: Random House. 
Haugeland, J. (1985). Artificial intelligence: The very idea. Cambridge, MA: MIT Press.

ITS-88 Montreal: Intelligent tutoring systems: Systemes $d$ 'enseignment intelligemment assistespar ordinateur. (1988). Montreal, Canada: Universitede Montreal.

Keamley, G. P. (Ed.) (1987). Artificial intelligence and instruction: Applications and methods. Reading, MA: Addison-Wesley.

Lawler, R., \& Yazdani, M. (Eds.) (1987). Artificial intelligence and education. Volume 1: Learning environments and tutoring systems. Norwood, NJ: Ablex Publishing.

McCalla, G. I., \& Greer, J. E. (1987). Thepractical use of artificial intelligence in automated tutoring: Current status and impediments to progress. (Research Report 87-2) Saskatoon, SK: University of Saskatchewan, Department of Computational Science.

Newell, A., \& Simon, H. A. (1972). Human problem solving. Englewood Cliffs, NJ: Prentice-Hall.

Norman, D. (1983). Some observations on mental models. In D. Gentner \&A. Stevens (Eds.), Mental models (pp. 7-14). Hillsdale, NJ: Lawrence Erlbaum Associates.

Norman, D. \& Draper, S. (Eds.). (1986). User centred system design. Hillsdale, NJ: Lawrence Erlbaum Associates.

O'Shea, T., \& Self, J. (1983). Learning and teching with computers: Artificial intelligence in education. Brighton, UK: Harvester Press.

Park, O., Perez, R. S., \& Seidel, R. J. (1987). Intelligent CAI: Old wine in new bottles, or a new vintage? In G. P. Kearsley (Ed.), Artificial intelligence and instruction: Applications and methods (pp. 11-45). Reading, MA: AddisonWesley Publishing Company.

Pinker, S.,\& Mehler, J. (Eds). (1988). Connections and symbols. Cambridge, MA: MIT Press.

Poison, M. C., \& Richardson, J. J. (Eds.) (1988). Foundations of intelligent tutoring systems: Lessons learned. Hillsdale, NJ: Lawrence Erlbaum Associates.

Self, J. (Ed.) (1988). Artificial intelligence and human learning: Intelligent computer-aided instruction. New York, NY: Chapman and Hall.

Slatter, P. E. (1987). Buildingexpert systems: Cognitiveemulation. Chichester, UK: Ellis Horwood Limited.

Sleeman, D. \& Brown, J. S. (Eds.). (1982). Intelligent tutoring systems. New York, NY: Academic Press.

Swigger, K. M. (1985, March/April). Intelligent tutoring systems: A tutorial. AEDS Monitor, 23(9-10), 6-9.

Waldrop, M. M. (1987). Man-mademinds: The promise of artificial intelligence. Rexdale, ON: John Wiley and Sons.

Wenger, E. (1987). Artificial intelligence and tutoring systems: Computational and cognitive approaches to the communication of knowledge. Los Altos, CA: Morgan Kaufmann. 
Woolf, B. (198a). Intelligent tutoring systems: A survey Survey lectures from the American Association of Artificial Intelligence 1986-1987, pp. 1-43. Los Altos, CA: Morgan Kaufmann.

Woolf, B., \& McDonald, D. (1985, March/April). Building a computer tutor: Design issues. AEDS Monitor, 23(9-10), 10-18.

AUTHORS

Peter Holt is an Assistant Professor in Computer Science at Athabasca University, Box 10000, Athabasca, Alberta TOG 2RO.

Peter Wood is a PhD. candidate in Secondary Education at the University of Alberta. 
124 CJEC SUMMER 1990 


\title{
Conceptualizing Hypermedia Curic ula for Literary Studies in Schools
}

\author{
Alister Cumming \\ Gem Sinclair
}

\begin{abstract}
Thls paper analyzes four innovative hypemedia programs for literary studies in schools, distinguishing and evaluating their cumculum orientations. Two divergent tendencies are evident. One tendency is to use hypermedia to enhance conventional instructional practices, improving the media for classroom interaction but offering little which is fundamentally new for student leaming, the context of literary studies, or the processes of instruction. The second, more radical tendency is to create "hyper-environments" which restructure the social contexts for literary studies to provide students direct access to relevant expert knowledge, higher orders of thinking, and greater control over their own leaming processes. This more radical approach offers profound potential for education, although its implementation may be constrained by existing educational structures and practices.
\end{abstract}

The application of hypermedia to literary studies in schools promises to further educational goals of critical interpretation, sophisticated use of language, aesthetic appreciation, and awareness of cultural traditions. However, literary studies are less obviously "teachable" than other parts of the curriculum, where learning goals and instructional procedures may be more easily defined - and thus modeled readily in interactive software programs. Empirical research has found it notoriously difficult to understand how students learn from literature in school, providing only exploratory insights into this phenonemon (Dias, 1986; Marshall, 1987; Nespor,1987; Squire,1964). Similarly, studies of the knowledge which teachers use to teach literature in schools reveal an array of complex, intuitive processes (Elbaz, 1983; McGregor \& Meiers, 1983), which are probably too diverse to model explicitly

It is already evident that there are two fundamentally different approaches to the use of hypermedia for literary studies in schools. One approach preserves conventional instructional practices, but enhances them through computer-based interactive media; this choice may provide little which is new in the way of educational experience. The second approach entails a more radical reorganization of conventional curricula, especially interactions be-

CJ EC, VOL 19, NO. 2, PAGES 125 · 137, ISSN 07104340 
tween students, following the lines proposed by Nelson (1987). This choice offers exciting potential, but may entail too radical a departure from current educational practices for general acceptance. In many respects, the two approaches of hypermedia implementation exemplify what Papert (1987) defines to be the "centra1 question for educators.. .whether schools of the future will go on teaching the same curriculum, using computers to do the job better, or whether we'll see radical change in what is taught and what is learned in schools"(p. xxxv).

The more radical approach to hypermedia implementation in schools requires the creation of "hyper-environments" for study and learning. Here, conventional classroom routines for rehearsing skills or reciting information are superseded by interactive communities of learners engaging in complex, dynamically linked tasks. The students themselves define the relevance of these tasks within a shared, computer mediated context. These hypermedia contexts provide access to relevant knowledge and facilities to integrate and develop new learning.

The present article develops a conceptual framework to guide and assess the implementation of hypermedia programs in schools. We review four projects which have recently developed innovative classroom applications of hypermedia for literary studies. Each project proves to have exploited the educational potential of hypermedia in unique ways. We consider these differences in view of distinctions, commonly made in curriculum analysis (e.g., Miller \& Seller, 1985), among conceptions of learning, teaching, content, and social context. These distinctions reveal different orientations to school curricula in each program, orientations which may significantly foster or constrain the benefits of hypermedia in educational practice.

It is worth noting that none of these programs conceives of learning in the rudimentary modes of drill-and-practice or simple skills rehearsal, which have featured in many programs for conventional micro-computers (Mehan, 1984). This may suggest that the technical complexity of interactive hypermedia tends to counter the reduction of learning to rote tasks, or it may be that the program designers who are adventurous enough to have attempted these innovations are, thus far, wary of such narrow conceptions of learning.

\section{FOUR EXEMPLARY PROGRAMS}

We have selected four exemplary hypermedia programs for analysis, drawing from among the few existing ones for literary studies in schools that we are aware of. At the time of writing, each program was in a preliminary stage of development. Future refinements are envisioned and, in most cases, are currently under way, some of which may date the present analysis out of date. We describe the principal features of each program, then assess their relation to the established curriculum. Our analysis is restricted to information reported in written documentation on each program, not from our 
hand evaluations of the programs in use in schools. We have used a broad definition of hypermedia as a system which supports "non-sequential writing" or "online dynamic text" in multiple media (Conklin, 1987; Nelson, 1987). Some of the programs do not adhere strictly to a narrower definition of hypermedia, requiring that all information in the system can be browsed through bidirectional links. But it is relatively easy to see how this could be achieved through modifications in the particular instances.

The four programs are:

"Grapevine (Campbell, 1989; Campbell \& Hanlon, 1988)

${ }^{\star}$ Gulf Islands Novel Study Project (Vine, 1988)

¿CSILE Book Club (Swallow, Scardamalia \& Olivier, 1988)

"Electronic-writer-in-residence (Owen, Kearns et al., 1988)

Grapevine (Campbell, 1989; Campbell \& Hanlon 1988) is an interactive array of multi-media material to supplement high school study of John Steinbeck's Grapes of Wrath. The HyperCard-based program incorporates more than 54 works, illuminating the "social and political history of the 1930s." These include: "books, films, television documentaries, still photographs, recordalbums and sound tapes, filmstrips, magazine and newspaper articles, and more" (p. 169). Information relevant to the social context of the novel is indexed by 33 topics, making possible at least 1,836 links between topics like "dust bowl," 'alien labor," or "New Deal," the novel itself, and the various media resources,

Annotations, suggested teaching activities, and references are provided, in addition to a system for "skimming through the material, browsing, searching, or studying it thoroughly" (p. 60). The project provides extensive resources in different media for study of social issues relevant to the novel. It presumes that 'a teacher deals with a novel not as an isolated piece of literature, but as one reflecting the times, the issues, and the author and other writers, artists, thinkers, and survivors" (p. 60) of the historical period. Developments are presently under way to make the program user-adaptive by providing facilities like on-screen note pads and authoring systems for use by individual teachers or students (Campbell, 1989).

The Gulf Islands Novel Study Project (Vine, 1988) provides a generic format to guide children's analyses of novels, using print and graphics media. It consists of hypermedia templates which, for any given novel, prompt students to: produce analyses of characters and plot; write critical reviews; prepare and integrate background information about an author; and answer hypothetical questions posed by a teacher (called "What if?"). For a specific book, students supply relevant information under each category using text, schematic, and pictorial forms. Links across media and topics are automatically established for users as they work with the program.

A demonstration version shows children's uses of the program to report on their interpretations of E.G. White's Charlotte's Web and George Selden's The 
Cricket in Times Square. Pedagogically, the program aims "to be simple enough for first-time student users to use, and for teachers to easily modify to suit their students' needs"(p. 1). Technically, the program is designed "to keep the stack small enough that it could be used with a minimum of storage space in a maximum number of hardware configurations." (p. 1) Students are expected to use the program to "actively interact to display their skills, ideas and understanding” (p. 3).

The CSILE Book Club is one aspect of a larger project developing and piloting computer-supported intentional learning environments (CSILE) for schools (Scardamalia, Bereiter, McLean, Swallow \& Woodruff 1989). For literature study, grade 5 and 6 students prepare reviews of different novels and then enter their reviews into a collective data base. Chart facilities, linked to the text media, also permit students to create graphics to accompany their reviews. Books are chosen by the students; reviews are written to interest other students in reading the books. Students meet in groups to interpret, critically assess, and try to learn from one anothers' reviews (Woodruff, et al. 1988). Their discussions and interactions with the computer texts are prompted by on-screen cues guiding the children's thinking toward: high level questions; summaries of their existing knowledge; new insights; bases for agreement and disagreement; plans for further study; and so on.

Students append critical comments to the original reviews through onscreen notepads. Original drafts of the reviews are then revised by their authors, incorporating the peer feedback, to pass from a preliminary "candidate" status to a final "published" status, as judged by peer consensus. The completed reviews are then "catalogued" in the larger data base (by students) using a special propositional syntax (based on keywords and logical 'arguments' accessible to children). Students are also asked to determine principles for effective book reviewing, based on their assessments of their peers' collective work.

The computer's procedural supports for the discussion groups derive from earlier research on cooperative reading with children (Swallow, Scardamalia \& Olivier, 1988). Students' thinking strategies while reading and discussing new texts were evaluated and modeled on adults' strategies. Pairs of students were assignedjoint roles as "directors" or "actors";)) directors aimed to draw out relevant knowledge, conceptual problems, and new learning from the actors. Based on analyses of these interactions, prompts were written to foster optimal thinking strategies, using the computer program to guide students' discussions, without adult support. The aims of the program are to foster "intentional learning" (Bereiter \& Scardamalia 1987), applying principles from recent research in cognitive science to direct children's development of higher order thinking and self-control.

The Electronic-writer-in-residence (Owen, Kearns, et al., 1988) set up an on-line computer conference for poetry writing and commentary among grade ten students in Toronto, a poet in Vancouver, as well as other high school students in Vancouver and writers in other locations, Drafts of poems were 
submitted by students and the "resident" poet, collectively critiqued, then revised for further display. The project lasted 5 months, compiling computer interactions which are catalogued and available for wider distribution by diskette. Above and beyond the fostering of creative writing, the rationale for the computer networking was to provide an "equity of use, placing students in control of what to write, when and where to 'send' it, and how to respond" (Owen, 1988, p. 1). In evaluating the project, Owen \& Kearns (1988, p, 8) consider participants learned much about "human interaction, communication, publication (making our work public), and the nature of this strange and wonderful medium that connects us in such intimate ways across the continent."

\section{CURRICULUM ORIENTATIONS}

These applications of hypermedia are innovative in different ways, each devising very particular applications for specific issues in educational studies of literature. Though it is clear that hypermedia applications for literary studies in schools are still in a preliminary stage of development, the diversity of these few programs is, we think, instructive. A closer, comparative analysis of their curriculum orientations reveals much which might not be apparent from our previous outline of their principal features.

\section{Instruction}

Instruction can be conceived as the transmission of information, This orientation is most evident in the Grapevine project, particularly in its early phases before the development of student personal notepads and individual authoring tools. Initial reports on Grapevine emphasize how hypermedia can enhance the potential to convey relevant data in different media to students. A second orientation is to consider instruction as the transaction of information In the CSILE Book Club and the Electronic-writer-in-residence project, information is negotiated, through and around the hypermedia interface, by classroom participants. Instructional supports appear in CSILE's procedural prompts or the Electronic-writer-in-residence's feedback. But this occurs in response to decisions established principally by students themselves. In the Novel Study Project, students' transactions of information occur outside of the hypermedia environment, while reading or researching information. Hypermedia is used later, to display students' achievements rather than to mediate or convey them. This might be called a demonstrative orientation to instruction, where tasks are completed for students to display information in the form of an achieved product.

\section{Content}

In the two projects which focus on the study of novels, the books themselves (i.e., Steinbeck's Grapes of Wrath or White's Charlotte's Web) provide concrete curriculum content, whereas in the Electronic-writer-in-residence the emphasis is on how students generate their own material (poems) as content. The 
CSILE Book Club divides its concerns between the processes of writing and revising book reviews and the study of various novels. Students' thinking strategies are thus given equal emphasis with the objects of study.

The modes for organizing curriculum content likewise differ. Grapevine and the Novel Study Project aspire toward an encyclopedic organization of content relevant to single novels. Thorough study of one literary item, and its related features, is aimed at. In contrast, the Electronic-writer-in-residence project and CSILE organize curriculum content in more of an episodic mode. Individual poems or book reviews produced by students serve to determine the curriculum content, creating a diverse, dispersed content for deeper analysis.

\section{Learning}

Different conceptions of students' learning underpin the four programs. In Grapevine, learning is considered to occur mainly through students' compilation and integration of knowledge. Hypermedia serve to foster students' bringing together of interrelated information into coherent conceptions. Though knowledge compilation does feature to some extent in CSILE, the Electronic-writer-in-residence, and especially the Gulf Islands Novel Study Project, these programs present goals for student learning which aim to model higher orders of thinking by providing developmental supports in complex tasks.

In CSILE, strategic supports for thinking are synthesized into procedural facilitations on the computer screen, which guide the social supports of peer discussions and self-analysis. Peer feedback likewise serves to foster reflective thinking and self-awareness of performance. In the Novel Study Project, a more general and conventional set of rhetorical organizers direct student performance on specific tasks and appear through the teachers' questioning about hypothetical situations. In the Electronic-writer-in-residence, the responses of an experienced poet and of peers to students' writing serve to model expert thinking in relation to their own work.

Except for the early versions of Grapevine, complex computer-baaed writing skills also feature as a substantial basis for learning, prompting student practice, analysis, and refinement of thinking. CSILE and the Electronic-writer-in-residence appear, however, to be the only two programs which provide a concrete basis for students' development of self-control over their own learning. The Novel Study Project presents task performance in the hypermedia environment as the end point of student activity, providing little support for learning to extend to other contexts or to be assessed strategically during the learning process.

\section{Social Context}

One can approach this issue by distinguishing between hypermedia contents that areprogram-generated, teacher-generated, orstudent-generated. This distinction is important for issues like teacher adoption, preparationtime, and curricular flexibility (see Riel Miller-Souviney, 1984). Grapevine, 
for instance, has been developed as a resource containing massive quantities of information. Without the authoring system now being developed its sheer quantity of information may make it difficult for teachers or students to use in classroom instruction. Similarly, CSILE provides a complex environment for learning and student interaction, such that teachers may find it difficult to integrate into existing routines for classroom study, without significantly reorienting conventional conceptions of student learning or instructional organization. For instance, Cumming's (1988) study of two experienced teachers using the program found that it took about six months for them to successfully intregrate CSILE into their teaching routines. New systems of classroom management, interaction, and assignments had to be established. Concrete obstacles to adopting the hypermedia curriculum" included: learning how to intregrate it with the conventional curriculum; having to account for students' achievements in new ways; and reallocating students' schedules to complete tasks.

In contrast, the Novel Study Project offers simple technical and pedagogical formulae, making it easily transposable from teacher to teacher, without requiring substantial modifications to conventional curricula. For the same reasons, though, it is unlikely that its introduction into classes would have much of an impact on changing the social context of learning in schools. This suggests that the other three projects come much closer to realizing the promise of hypermedia to offer genuine curricular restructuring.

CSILE and the Electronic-writer-in-residence are notable for foregrounding student input, decision-making, and interaction, thereby providing an environment for students to assess and advance their existing knowledge. The organizational structure of these two programs require that the hypermedia create environments for literary study which are self-sustaining and pedagogically interactive, without the need for teacher-dominated instruction usually conducted in schools.

This distinction marks the major issue in the development and implementation of hypermedia programs for literary studies in schools. The relationships of hypermedia to the social contexts of education suggest that a central factor in program design and implementation is the matter of who a program enables to make principal decisions about classroom study and learning students, teachers, or the program? If the substantive content and uses of a program are largely pre-determined, as in off-the-shelf, commercially available hypermedia courseware packages, these may be difficult for teachers to adopt to their usual practices or students to integrate with their studies of other literature. If teachers are prompted to determine the content and uses of hypermedia, following conventional practices (as in the Novel Study Project), it is probable that the potential uses of hypermedia will be reduced to task routines which are not, fundamentally, unlike those now occurring in classrooms using less sophisticated media.

In view of these problems, it appears that the two projects (CSILE and Electronic-writer-in-residence) which require innovative restructuring of 
social relations among students, teachers, and the hypermedia may be the optimal means for attaining hypermedia's educational potential. Students are put in the position of making decisions about their own learning and social interactions - the hypermedia environments guiding them toward appropriate learning goals. From a teacher's viewpoint, however, these programs may be considered too time-consuming or unusual to manage within the routines of teaching they have already established. Practical issues like time allocation, the physical organization of the classroom, and students' work schedules need to be restructured and established anew.

\section{SUMMARY AND IMPLICATIONS}

The major issue which emerges from our analysis of the curricular impact of these innovative programs concerns the extent to which hypermedia programs might, or really can, reconceptualize approaches to literary studies in schools. The greatest promise to achieve this goal appears in programs, such as the CSILE Book Club or the Electronic-writer-in-residence, which use hypermedia environments to create functional contexts for learning and interaction far beyond those practiced in conventional classroom instruction. These programs come closer to realizing the profound changes in society's exchange of information envisioned in Nelson's Literary Machines (1987). Hypermedia create educational contexts which differ qualitatively from ordinary schooling -- supporting learning which is student-generated and transacted, directly linked to relevant expertise, episodically managed and integrated, and cognizant of its own emerging existence and terms of reference.

Alternatively, there are models for the development of hypermedia programs which conform more closely to conventional instructional practices retaining their fundamental characteristics, but enhancing their presentation or multiplicity. In this sense, Grapevine functions much like a rapidlyaccessed, topically-organized, multi-media library. The Gulf Islands Novel Study Project extends usual instructional formula for student assignments into hypermedia formats. In either case, literary studies are conceived mainly as the performance of routine analyses or the transmission of information, much as they usually are in schools. In these cases, hypermedia certainly provide a richer means of displaying student achievements or accessing multiple information sources. But expectations for student performance remain much as they would be without the hypermedia environment.

How can we expect these two routes to hypermedia implementation to fare in schools? Programs adhering to conventional curriculum models are likely to be well received. We can even expect them to emerge widely, in "grass roots" fashion, as innovative teachers adopt their usual practices to accommodate these new media (Aoki, 1987; Riel \& Miller-Souviney, 1984; Snyder, 1988). Such hypermedia programs present predictable and orderly tasks, which can be organized and accomplished neatly by teachers and students with little deviation from usual policies. 
At the same time, however, we can expect such hypermedia programs to miss the opportunities for learning available through the higher route designs. As recent research on the uses of micro-computers in classrooms has started to show, teachers as well as students tend to reduce the cognitive demands of classroom computer tasks in areas as diverse as: self-directed learning (Cumming, 1988); composing skills (Cazden, Michaels \& Watson-Gegeo, 1987; Dickinson, 1986); problem solving through Logo programming (Hawkins 1987); science projects (Martin, 1987); and school-to-school networking (Riel \& Miller-Souviney, 1984). Conventional curriculum models for educational computing quickly see computers come to function as "electronic work-sheets," having necessarily to fit into the usual organizational constraints and patterns of classroom instruction (Mehan, 1984).

On the other hand, the educational potential of the higher route hypermedia programs is enormous. We might see their value in their restructuring of the social contexts of learning so as to create a "mindfulness" (Salomon, 1986) in students which is capable of producing higher orders of thinking, access to expert knowledge sources, and self-control of learning processes. But is a restructuring of educational contexts necessary to achieve such aims? Looking at the few case studies describing effective implementation of hypermedia in other settings, it would appear that this is so. At least, it has been reported as such for technical writing (Barrett \& Paradis, 1988), multilingual international networking (Cohen, Levin \& Riel, 1985), university composition (Slatin, 1988) or literature study (Garrett-Petts 1988). In each instance, project reports have described how new patterns of organization, functional roles, and human dynamics have necessarily accompanied effective introduction of particular hypermedia into these instructional circumstances.

This makes us wonder how such restructuring might be feasible, on a broad scale, amid the conservative and conserving forces of schooling. Will teachers, students, school administrators, consultants, policy-makers, and parents support a nearly anarchistic organization of groups of learners pursuing individually-determined aims? What will the perceived achievements of learning be, and how could they be evaluated? How will forces of educational conservatism -competency tests, standard curricula, or established policies - confront such a radical departure? How could such restructuring be introduced equitably across socio-economic levels, given the costs, supports, and teacher development required (Sheingold, Martin \& Endreweit, 1987)?

These questions, we believe, are the real challenge of hypermedia innovations for educators. None bear easy answers. Our analysis can, in closing, only offer several principles to guide hypermedia developments of more conventional curriculum models, gently toward the higher road-by suggesting they aim to provide students with:

access to, and integration of, quantities and qualities of information not usually accessible through a single medium or conventional instruction; 
the means to engage purposefully in the transaction of information in relation to their existing knowledge and skills, above and beyond the transmission of new information and the display of achieved tasks;

- a functional learning environment around the computer interface, involving the allocation of shared responsibilities and goals among groups of users;

- $\quad$ supports to foster individual organization and decision-making leading to increased self-control;

- $\quad$ prompting of higher orders of thinking about literary material; opportunities to model peer and adult learning processes not usually offered in schools.

Ultimately, we find ourselves in agreement with Cynthia Solomon (1988) who points out that "different computer environments give rise to different computer cultures." Solomon argues that "children and teachers who are learning to use computers need to develop an awareness of [these] different computer cultures, and they must blend these cultures to create their own." (p. 13). We find it useful to substitute the term "hypermedia" for "computer" in Solomon's statement for, in fact, a hypermedia environment is one in which a computer drives and integrates the nonlinear interaction between learners and a variety of different information media. Within this context, we suspect that the most successful implementations of hypermedia programs in schools will be the ones in which teachers and students create their own cultures supported by non-traditional, "hyper-environments" for learning.

\section{REFERENCES}

Aoki, T. (1987). Toward understanding "computer application." Journal of Curriculum Theorizing 7(2), 61-71.

Barrett, E., \& J. Paradis. (1988). The on-line environment and in-house training. In E. Barrett (Ed.), Text, context, and hypertext: W riting with and for the computer, pp. 227-249. Cambridge, MA: MIT Press.

Bereiter, C. \& M. Scardamalia. (1987). An attainable version of high literacy: Approaches to teaching higher-order skills in reading and writing. Curriculum Inquiry $17(1)$, 9-30.

Campbell, R. (1989, March). (I learned it) through the Grapevine: Hypermedia at work in the classroom. American Libraries, 200-205 .

Campbell, R., \& P. Hanlon. (1988). Grapevine. In S. Ambron \& K. Hooper (Eds.) Interactive multimedia: Visions of multimedia for developers, educators, and information providers, pp. 159-177. Redmond, Washington: Microsoft Press.

Cazden, C., S. Michaels \& K. Watson-Gegeo. (1987). Final report: Microcomputers and literacy project. (Grant no. G-83-0051). Washington, D.C.: National Institute of Education. 
Cohen, M., J. Levin, \& M. Riel (1985). The world as functional learning environment: An intercultural learning network. La Jolla, CA: Center for Human Information Processing, University of California, San Diego.

Conklin, J. (1987). Hypertext:An introduction and survey Computer 20(1), 1741.

Cumming, A. (1988). Change, organization and achievement: Teachers concerns in implementing-a computer learning environment. Journal of Educational Technology Systems 7(2), 141-163.

Dias, P. (1986). Making sense of poetry: Patterns in the process. Ottawa: Canadian Council of Teachers of English.

Dickinson, D. (1986). Cooperation, collaboration, and a computer: Integrating a computer into a first-second grade writing program. Research in the Teaching of English 20(4), 357-378.

Elbaz, F. (1983). Teacher thinking: A study of practical knowledge. London: Croom Helm.

Garrett-Pet@ W. (1988). Developing a community of readers: Computer networking in the freshman literature class. English Quarterly 22 (l), 2940.

Hawkins, J. (1987). The interpretation of Logo in practice. In R. Pea \& K. Sheingold (Eds.), Mirrors of mind: Patterns of experience in educational computing, pp. 3-34. Norwood, NJ.: Ablex.

Marshall, J. (1987). The effects of writing on students' understanding of literary texts. Research in the Teaching of English. 21 (l), 30-63.

Martin, L. (1987). Teachers' adoption of multimedia technologies for science and mathematics instruction. In R. Pea \& K. Sheingold (Eds.), Mirrors of mind: Patterns of experience in educational computing, pp. 35-56. Norwood, NJ: Ablex.

McGregor, R., \& Meiers, C. (1983). English teaching in practice. Sydney: St, Clair Press.

Mehan, H. (1984). The current state of microcomputer use in schools, In H. Mehan \& R. Souviney (Eds.), The write help: A Handbook for computers in classrooms, pp. l- 14. La Jolla, CA: Center for Human Information Processing, University of California, San Diego.

Miller, J. \& Seller, W. (1985). Curriculum: Perspectives and practice. NewYork: Longman.

Nelson, T. (1987). Literary machines, 5th ed. Swarthmore, Penn.: Project Xanadu.

Nespor, J. (1987). Academic tasks in a high school English class. Curriculum Inquiry 17(2), 203-228.

Papert, S. (1986). Logo as a Trojan Horse: Reflecting Logo philosophy in the context of real school experience. Logo86 Conference Pre-Proceedings, pp. xxxiv-xxxvi, MIT, Cambridge, Mass.

Owen, T., Kearns, L., et al. (1988). Computers and Word Processing in the English Classroom, 3(1), Riverdale Collegiate Institute, Toronto. 
Riel, M. , \& B. Miller-Souviney. (1984). The introduction of microcomputers and the possibility of change. In H. Mehan and R. Souviney (Eds.), The write help: A Handbook for computers in classrooms, pp. 35-55. La Jolla, CA: Center for Human Information Processing, University of California, San Diego.

Salomon, G. (1986). Information technologies: What you see is not (always) what you get. Research report no. 3. Tel Aviv University.

Scardamalia, M., Bereiter,C. , McLean, R., Swallow, J., \& Woodruff, E. (1989). Computer-supported intentional learning environments. Journal of Educational Computing Research, 5 (1), 51-68.

Sheingold, K., Martin, L., \& Endreweit, M. (1987). Preparing urban teachers for the technological future. In R. Pea \& K. Sheingold (Eds.), Mirrors of mind: Patterns of experience in educational computing, pp. 67-85.

Slatin, J. (1988). Hypertext and the teaching of writing. In E. Barrett (Ed.), Text, context, and hypertext: Writing with and forthecomputer, pp. 111-129. Cambridge, MA: MIT Press.

Snyder, T. (1988, August-September). Tools for teachers. The Computing Teacher, 8-16.

Solomon, C. (1988). Computer environments for children: A reflection on theories of learning and education. Cambridge, MA: MIT Press.

Squire, J. (1964). The responses of adolescents while reading four short stories. Champaign, IL: National Council of Teachers of English.

Swallow, J, Scardamalia, M., \& Olivier, W. (1988). Facilitating thinking skills through peer interaction with software support. Paper presented at the annual meeting of the American Educational Research Association, New Orleans.

Vine, K. (1988). HyperCard in literature: Applying hypercard to a grade four readingprogram. Ganges, B.C.: Saltspring Island Elementary School.

Woodruff, E. and the CSILE research and technical group. (1988). CSILE report noting progress to March 31, 1988. Toronto: Centre for Applied Cognitive Science, Ontario Institute for Studies in Education,

\section{APPENDIX A}

Technical aspects of the four programs are as follows:

The Gulf Islands Novel Study Project uses HyperCard stacks as templates, which are set at "scripting" to permit browsing and adaptations by users. Graphics are collected on MacPaint and FullPaint and can likewise be altered by users. CSILE was designed for UNISYS ICONS (for Ontario schools) but has recently been implemented on Mac II's and SUN workstations. A fileserver links 16 student stations equiped with their own RAM. Files are contained in a common root directory or users' home directories, forming a group database of (1) 'public' files accessible to all users and (2) 'private' files for individual 
users, which may be stored in either location. Prompts, icons, and keywords store data in textual and chart forms, as well as providing interfaces for users in specific environments like: "new learning", "planning", "questioning", or "timelines". The Grapevine project runs on a Macintosh Plus linked to a Pioneer 4200 videodisc player and monitor, using headphones for sound. HyperCard software controls the program, using a guide stack for browsing. Plans are underway to make the program available commercially (Campbell 1989). The Electronic - writer - in - residence project was set up as an online interactive computer conference which runs on the Simon Fraser University computer Network on an IBM 3081 mainframe under release 6.OD of the MTS operatingsystem. The computer conferencingsoftware which runs under MTS is called *Forum. Participants (students, teachers, and poet) accessed the conference using a variety of microcomputers (Macintosh, IBM PCs and UNISYS ICONS) with many different communication software packages and 1200 baud modems.

\section{AUTHORS}

Alister Cumming is Assistant Professor, Department of Language Education, 2165 Main Mall, University of British Columbia, Vancouver, BC V6T 125. Gerri Sinclair is Adjunct Professor in the Faculty of Education, Director of EXCITE, and consults internationally on interactive media and technology.

\section{ACKNOWLEDGEMENTS}

We thank Paul Delany and CJEC reviewers for their detailed suggestions to improve an earlier version of this paper. 
138 CJEC SUMMER 1990 


\title{
Point
}

\section{Saying "NO" to Computers in the Classroom}

\section{RANDLE W. NESEN}

\begin{abstract}
Computer-based school instruction moulds students to unliberating, professionalized bureaucratic routines and it should be resisted. Differences between electronic and print culture are emphasized In order to examlne schooling within a hidden curiculum encouraged by the main technological drift of cultural homogenization. It is argued that the widespread introduction and use of computers in the classroom will not counter the dangers, and change the direction, of this drift; rather, classroom computer use, as is the case outside schools, will foster a technocratic mentality, a machine-as-master mind set, among school participants who are supportively reformulating status-quo arrangements. Schools, which as Instltutlons are still behind the electronic times, offer us a sort of last chance to begin resisting the main technological drift by beginning to develop individualized voices, grounded in community and regional uniqueness, that would further actualize local autonomy and control.
\end{abstract}

For perhaps the tenth time over the past eighteen months I am seated at my study desk triangled by three large piles of notes. I am ready to write about technology and human liberation, specifically about the use of computers in our schools, but I am blocked and the sheets of paper before me remain blank. I teach courses entitled "Technology and Society", "Computers and Society", and "Sociology of Education"; I usually have plenty to discuss with my students but I just can't seam to get what is important to me onto paper. Then I realize that what moved me in these often-heated discussions is the general feeling that much of what I hold dear, as well as much of what gives me personal satisfaction, seems threatened by widespread implementation of the latest technology. Ah, finally, a place to start -perhaps if I begin with the people and things I love most, I'll be able to write.

\section{FROM A CORNER OF MY ROOM: MUSINGS ON TECHNOLOGY, CREATIVITY, AND CONTROL}

My gaze focuses upon that corner of the room which is special to me. On the wide shelf next to the old portable television are a basketball and some 
momentos from various city league seasons; next to these is a stereo with a stack of my favorite records alongside; finally my gaze moves over to several photographs of my friends and family- including one of my youngest daughter taken only a few hours after she was born.

The basketball near the T.V. reminds me that I have been watching less televised basketball these days. I still love the game but what really irks me are the "television time-outs" -those breaks that no longer come from the ebb and flow of the emergent human interaction as it develops among the players and coaches of the game, but rather from the networks' financial commitments to serve the game's corporate sponsors. Something of value to me as a fan and a player has been lost and neither I nor the televised participants seem to be able to recover it and control it. I suppose one could argue, in the professional ranks at least, that the players have opted for the progressively higher salaries which got the big money sports-snowball rolling and so they have chosen to forfeit control, although this line of argument is just about as invalid and unsatisfying an explanation as blaming workers and unions for rapid cost of living increases and inflation. In brief, such an explanation leaves out more than it tell us about the ways each of us is personally affected by the interactive workings and arrangements of the larger socio-economic structure.

More directly relevant to the control which emanates, in large measure, from the technology itself, is the manner whereby the camera narrowly dictates which part of the live action the televised fan will follow. Since the "live action" camera almost always follows the interaction around the ball the T.V. spectator is forced, at least until the instant replay using another camera, to miss much of the play off the ball as well as, and most importantly, the gestalt of seeing both the on-ball and off-ball interaction live or together as one moment. This is why being a T.V. spectator is something other and more than simply another step removed from actually playing the game-why being a T.V. spectator is a qualitatively different experience than being an on-site spectator, a part of the live performance.

My eyes and mind move to my records, some of which date back to the early 1950 s. Missing many nuances and the gestalt of a basketball game through the narrowed perspective of the television camera brings to mind a recent analysis by Mark Hunter (1987) concerning the impact of new technology in recording rock music over the past thirty years. Hunter chronicles the movement from monophonic taping to stereo multitracking, showing how the song and sound content of rock has become almost exclusively a product of the recording techniques dictated by implementation of the latest technology. In brief, stereo multitracking means that composition is unlocked or untied from -that is, it doesn't depend upon live performance together as a group.

Glancing up from these pages to gaze again for a long moment at the photograph of my youngest daughter, I realize that the new technology surrounding human conception and birth, like the latest record-making technology, is changing the cast of players and the emergent interactive processes among them. As with multitracking musicians, the new technology 
of embryo transfer eliminates the necessity for all the participants to be present at, or in this case even contribute to, conception. Thus, it might be argued that the latest technology may give both prospective parents and musicians the joy of a freedom unknown to earlier generations. This argument should not be used, however, to suggest that the artist or creator enjoys a growing measure of artistic control. Rather, on the contrary, with these cases and to a more limited extent with basketball players who are televised, a measure of control formerly in the artist's possession passes from the artist to the technology. Artist or creator becomes technologist and as the work of the late Marshall McLuhan (1964;1967), among others, emphasizes, form shapes and becomes content as the medium becomes not only the message but the massage.

\section{COMPUTERS AND CULTURAL HOMOGENIZATION: TECHNOLOGIZING STUDENTS AND ROCKERS}

This process whereby creating artist is turned into engineering technologist is only part of the story. It is important not only in itself but also as symptomatic of a much more widespread cultural malaise, the drift towards worldwide cultural homogenization. The late George Grant (1969, p.26), with serious good humor, wrote about the consequences of our continued encouragement of this drift:

As for pluralism, differences in the technological state are able to exist only in private activities: how we eat; how we mate; how we practise ceremonies. Some like pizza, some like steaks; some like girls, some like boys; some like synagogue, some like the mass. But we all do it in churches, motels, restaurants indistinguishable from the Atlantic to the Pacific.

In a similar vein and I hope in a way which contributes something to Grant's discussion of technological homogenization, I have criticized schooling as socialization that standardizes emotions as well as analytic perceptions and in so doing, often diminishes or eliminates potentially important differences for the sake of moulding students to professionalized bureaucratic routines (Nelsen, 1985). The widespread advocacy and use of "computer-aided instruction" in our schools is more of the same.

The key to understanding what is wrong with the computer as instructional aid both within and outside the classroom involves the interconnections among collaboration in, demonstration of and the freedom one has in controlling her/his own learning. Educator Frank Smith (1986) in an excellent book: entitled Insult to Intelligence: The Bureaucratic Invasion of our Classrooms, has spoken to these connections in relation to computer-aided instruction. 
Smith situates the "drill and test" learning of production-line schooling that is favored by computer technology within the larger framework of a particular kind of behaviorist learning theory. Focusing upon language teaching he contrasts this "bits and pieces" learning- the fragmented, isolating and tightly controlled learning which treats human beings like pigeons pecking at keys -with the collaboration, demonstration and freedom which must necessarily accompany the apprentice-like learning he favors. Smith effectively underscores the point that learning simply accompanies, but in a very important way is quite incidental to, so-called "learning objectives". In brief, he argues that while a behaviorist learning model grounded in the systems analysis technology of highly specified objectives may have been important in putting humans on the moon, application of this same learning model has not and will not, even with the aid of computers, be effective in making students literate.

In the final analysis the crucial issue for both Smith and myself has to do with control. His concern, like mine, is that the computer is becoming just another means for further ritualizing and mechanizing a top-down direction which further abridges what little freedom is left to both students and teachers together to discover and satisfy their unique desires by developing their own styles of learning.

Should this concern seem to some readers as if it is overly pessimistic and an over-emphasis upon the passivity created by computer instruction, then it is important here to elaborate so as to more fully understand the larger social context within which computer-based school instruction takes place. This larger context encompasses the interconnections between the school and the widespread development and use of electronic media other than the computer as parts of a larger set of socioeconomic arrangements which encourage mass passivity. Elsewhere I have detailed the way in which bureaucratic and global corporations, as manufacturers of both computer hardware and the programmed-learning packages that accompany it, continue to dehumanize and depersonalize school culture by shaping a knowledge industry built in their image (Nelsen, 1975). An ally useful to these large corporations has been television, a medium which has prepared the way by encouraging our fascination with, and growing faith in, the technological fix of video-screen machines "teaching" programmed-learning packages to a T.V.-pacified audience. Like television, the little black box we call computer also comes with a point of view or a hidden curriculum that is embedded both in the structure of power relations governing production and distribution of hardware and programming, as well as in the form of the medium itself.

What results, in the cases of both computers and television, is increasingly homogenized programming for mass audiences who, like their producers, are ever more passive and pacified by a learning-as-product mentality rather than viewing and developing learning as an active process. For an indication of just how deeply entrenched and widespread is this passivity-oriented homogenization engineered through today's electronic media, I return to Hunter's (1987, 
p.57) analysis and his concluding paragraph on how the latest in multitrack recording technology has disastrously "flattened" rock music.

Close your eyes the next time you watch an MTV video, and you'll realize that the band could be anyone, which is to say no one. What rock video has confirmed is that rock music no longer requires an emotional - let alone physical -engagement on the part of its audience. It is merely something one watches, passively, without noticing its constituent elements. It is no longer worth listening to.

Here Hunter is drawing our thoughts a final time not only to the dynamism that is lost by the separation of composition and performance, but also he is clearly implying that attention to the video screen can be a mask which hides from the listening and watching audience much of what has transformed rock music. The new "clean-sounding" music has grown increasingly dependent upon costly equipment owned by a wealthy elite and the esoteric expertise of a few producer-and engineer-technicians. The result is promotion through the machine manipulation of record mixing in dance clubs with the hope of gaining entree to one of the few "live performance" clubs left in a vastly contracted club scene. What is left to musicians as artists or creators is a technological apprenticeship for a favored few "visual bands" whose music is purged of any idiosyncracies, its heterogeneity and humanness if you will, so as to be translatable into rock-videos.

In brief, this "clean-sounding", rock-video music is common or folk music, not in the sense that it is participatory music made by special folk representing localized or particularized ways of living, but only in that it represents the lowest common denominator - a flattened pre-packaged homogenization of life's more varied quality and qualities. It is made for nobody in particular by nobody in particular. It is music which truly has become Muzak. And, perhaps the saddest observation of all, it is this flattened-out, elevator-type Muzak which a large percentage of the general public as audience is now used to and has come to expect.

\section{COMPUTERS AND STUDENT EXPECTATIONS: A DISCUSSION OF THE MACHINE-AS-MASTER MIND SET, LITERACY, AND SOCIAL CHANGE}

What needs to be said about the student audience for today's computerbased instruction? What have they come to expect? One way of answering is to pose two or more questions. Is the oft-remarked upon potential of "the personal computer revolution" actually creating revolution in the sense that large-scale socio-economic arrangements are being fundamentally altered? At the very least, is the potential for personalizing instruction being realized in 
the sense that computer-based learning is helping to develop and meet personalized needs and tastes on either an individual and/or a community basis? The answer to both questions is "No".

The refinement of computer technology and the widespread implementation of computers in the classroom further support the lines of development and non-revolutionary change which foster a disturbing kind of technological or technocratic mentality, a machine-as-master mind set. It is this developing mentality which further discharges what should be our emotionally-charged spirituality, our sense of morality ifyou will. It is what makes it more and more difficult for us to find a principled place to stand - to know, through a developing sense of who we are as community members, what we stand for and why. And, as is argued below, it is a matter of survival value for individuals to develop a community-minded sense of place which at times literally forces them to say "No" - in a word, to counter, to do something other than simply to be caught up in passive support of the main technological drift.

According to evidence provided by Paul Olson (1985) and his associates, the main technological drift is usually supported when computers are introduced as part of the classroom curriculum. Computers as they are currently being used in the schools, and this is the case outside the classroom as well, seem to be increasing rather than decreasing economic, status and knowledge inequalities among groups. Their initial findings indicate that unless the computer is introduced in certain preferred ways its liberating potential, its potential to overcome the class, gender and ethnic biases of the hidden curriculum, is at best muted and often altogether lost. These observations by Olson and his team reaffirm and underscore a basic premise of current work in the sociology of education - namely, the importance of social context.

The best social contexts are those in which computer use is integrated as part of regular classroom activities and controlled at the local classroom level by students encouraged by the teacher and each other to collaborate in discovering and demonstrating the computer's advantages It is students and teachers together creating this kind of social context or atmosphere who are most likely to actualize whatever liberating potential computers in the classroom may have. However, as Olson et al. point out, it is precisely this kind of atmosphere which is most often not created, and much more frequently than not students continue to remain unliberated from the structural constraints of both the school's and technology's hidden curriculum,

What most students are taught from classroom computer use is much like what their television watching in general, rock-videos included, teaches them. They learn not to question but rather passively to accept the program, the message and the massage of a medium that isolates them by blurring and denying, by successfully homogenizing, different life situations. What is created is a computerized togetherness, a "network" to use the current lingo, which further isolates individuals in support of, rather than calling forth collaborative efforts to change, the status quo. In brief, the isolation fostered by the electronic media of computers, television and the like, encourages a 
passiveness and an acquired inability to image, to imaginatively unblur, possibilities for fundamental social change. All of this is not too surprising given evidence indicating that in typical Canadian homes conversations between adults and children usually take up less than thirty minutes a day, most of that time being limited to "don't" and "do" directives, and in which a machine that creates images for us is on for more than six hours a day What we have lost, to return to Smith's key terms, is the fredom, or perhaps more precisely the experiential or practical knowledge, to collaborate in demonstrating and creating a different present and future from the one imaged for us by the electronic media.

Reading, like using the electronic media of television and computers, may encourage a distancing and isolating individualism. However, it is critical to understand that the aloneness required of readers by print culture, unlike that fostered by the electronic media, is often accompanied by what Neil Postman (1982, p.77) has described in the literate person as "learning) to be reflective and analytical, patient and assertive, always poised, after due consideration, to say no to a text." Saying no to the authority of the printed word is crucially important to those of us interested in fundamental social change because it is often the first step in, the catalyst for, imaging alternatives to status quo arrangements.

Developing literacy skills (reading, writing, conversing, analytic thinking) that may result in this engaged interest in alternatives is itself dependent upon developing what Michigan educator Seymour Fader (1981) calls, "the voice in your ear." He argues that this voice is developed because on a regular basis one has been listened to, has been treated by family and friends as having something to say that it is worth listening to. This in turn teaches us how to listen to others both in conversation and in books. Given the role models available in the previously-described Canadian home, a home which is typically lacking in conversation and heavily involved with television, concerned observers might legitimately wonder about the probability of developing Fader's "voice in the ear," even with the new computer technology at hand.

It is the development of Fader's voice which makes one come to know that s/he exists as a legitimate person, a person who has something legitimate to say What is extremely troubling about the widespread use of computer technology is that in situating us as a people and culture more firmly in the electronic age, computer technology, like that of television and its rock-videos, further homogenizes a growing cultural sameness by a programming where, in Postman's (1982, p.79) words: "Everything is for everybody." Of course, this is in large part due to the nature of the television medium itself which, as is not as much the case with the computer, both requires and develops no skills. Still, neither the computer nor television, unlike reading, encourages the engaged participation that accompanies development of Fader's voice and even computer advocates, proponents of computer-based instruction, are concerned about this.

Sherry Turkle (1984), for example, has written about the "revolutionary" 
potential of turning away from a drill and practice kind of computer-aided instruction to a model of education where the child programs the computer to build something personalized - something over which s/he develops mastery and exerts control. Yet, even assuming this more creative use of the computer as an expressive and personalized learning device, Turkle is very concerned with the way in which the computer-age children she studies differ from their pre-computer parents. The heart of her concern is with the ruledrivenness of computers and their users. Interviewed on TVOntario's "Realities", Turkle (1985, pp.7-8) noted and warned:

.. If you look at video games, if you look at computer games, if you look at Dungeons and Dragons, what all of these worlds have in common is that they're rule-driven.. .And it troubles me that the style of this generation is so tied up in to a sense that behind the game, behind the behaviour there are the rules.. .And in these rule-governed fantasy worlds, again, it's very different from you be Boy Rogers, I'll be Dale Evans, I'll be a Nancy Drew, you be a Hardy Boy or the oldest game in town for children which is, you know, for time immemorial, Ill be the Mommy, you be the Daddy-that kind of game. Where the game is to not have rules but to empathize, to negotiate, to imagine what's inside another person's head, to create a social world where children learn that everything doesn't have rules.

It is precisely this failure to create a social world, a world where each individual knows that $\mathrm{s} /$ he as a person exists as part of a larger collectivity and is developing a meaning-filled and meaningful voice in engaged interaction with others, which troubles me most about widespread reliance upon computers within and outside the classroom. Whether it is drill and practice learning packages programmed by far-off experts with offices at corporate headquarters or at branch-plants in major metropoles, or the rule-driven creativity of child programmers in front of a terminal at a local public school in my hinterland city and region, learning where computers are the centerpiece of instructional activity is not likely to create either revolutionary or personalized social worlds.

What such learning is likely to encourage is our growing cultural ethos in which individuals are increasingly comfortable about having No Sense of Place (Meyrowitz, 1985). A learning and cultural character where individuals are increasingly blase' about their inability to develop even the small amount of liberating potential inherent in computer technology - a situation where individuals continue to accept a voice in the ear that increasingly homogenizes idiosyncratic experience by encouraging dependency and control from afar, rather than beginning to counter global economic and technological developments by developing an individualized voice grounded in a community and regional uniqueness that would further actualize local autonomy and control. 


\section{SUMMARY COMPUTERS AS CLASSROOM TECHNOLOGY AND THE PRACTICE OF SOCIAL SCIENCE AS PUBLIC PHILOSOPHY}

In sum, it should be clear that I oppose the widespread introduction of computer-based instruction in the classrooms of our compulsory-attendance schools. It is painfully evident to me that whatever liberating potential computers may possess is severely limited by the manner in which the prevailing socioeconomic arrangements of the computer industry and the technology of the medium itself together impose upon users. Widespread use of computers emphasizes that which is most damaging about our current overreliance, our fixation, on the latest in technology - specifically, the cultural homogenization that encourages our thinking about and worshipping of TECHNIQUE, in the social sciences this is often seen in a fascination with METHOD or METHODOLOGY as not only a means to some other end but, as an end in itself. Surely, we must ask why, for whom and at the expense of whom, as well as how? However, to do so means that we are asking moral questions -the kind ofquestions with which most people in the electronic age of television and computers, are quite uncomfortable.

Elsewhere I have suggested some starting points for a social science practice which by asking these questions would no longer ground itself in the ideological luxury of removing social science from social policy (Nelsen, 1984). Similarly, Robert Bellah et al. (1985, pp.297-307) also have argued for developingsocial science as public philosophy. To develop such a social science would mean creating and emphasizing an apprentice-like learning atmosphere where participants are free to collaborate and demonstrate their developing knowledge to and with one another. It would be a participatory learning where those inside school classrooms are practically connected to others neither by considerations dictated from the technology of the computer nor by computer "networking" that is an orchestrated result of the global economic concerns of transnational corporations, but instead, by common considerations and concerns originating in their local communities. Creation of such an atmosphere would mean continually asking the moral and philosophically-based "why" questions, not as part of abstract theoretical debate among "liberal" individuals in a "liberal" society, but rather, as matters of practical involvement among actively engaged individuals who share an understanding that they each are part of a larger community-based collectivity

Schools at all levels have never done much to create an atmosphere like the one just described and, I hope that this paper has clearly shown that the widespread implementation of computer-based instruction in the schools is not a step in the right direction. It is not merely happenstance that Grant (see, for example, 1969; 19861, a Canadian philosopher whose interest in the well-being of the collectivity stemmed in large measure from his strongly-held Christian faith, was in the forefront of those asking the "why" questions. It is not necessary, however, for all the rest of us interested in the collective well-being to embrace Christianity in order to develop progressive and change-oriented 
practice which is, like Grant's, out-of-step with the main technological drift of the times. To accomplish this what we do have to ensure are opportunities, both within and outside the classroom, for exchanging ideas about and experiences with computer technology as potential for human liberation. As for schools, if one of schooling's important tasks is to pass on to the next generation and at least sometimes question the old culture, the culture of print and literacy, than I for oneam very grateful for the few potentially liberating opportunities which may continue to be created through the recognition that schools, "computer revolution" included, are still behind today's electronic times.

\section{REFERENCES}

Bellah, R.N., et al. (1985). Habits of the heart: Individualism and commitment in American life. New York, NY: Harper \& Row.

Fader, S. (1981). For the sake of children without learning disabilities. Speech given at the QACLD conference, Hamilton, Ontario.

Grant, G. (1969). Technology and empire: Perspectives on North America. Toronto, ON: Anansi.

Grant, G. (1986). Technology and justice. Toronto, ON: Anansi.

Hunter, M. (May 1987). The beat goes off: How technology has gummed up rocks grooves. Harper's Magazine, pp. 53-57.

McLuhan, M. (1964). Understanding media. Toronto: McGraw-Hill.

McLuhan, M., \& Fiore, Q. (1967). The medium is the massage. Toronto, ON: Bantam.

Meyrowitz, J. (1985). No sense of place: The impact of electronic media on social behavior. New York, NY: Oxford.

Nelsen, R.W. (1975). Growth of the modern university and the development of a sociology of education in the United States. Unpublished doctoral dissertation, Hamilton, Ontario, McMaster University

Nelsen, R.W. (1984). The limits of bureaucratized scientistic professionalism and the potential of humanistic social science, part two. Human Affairs, 7, 81-101.

Nelsen, R.W. (1985). Books, boredom and behind bars: An explanation of apathy and hostility in our schools. Canadian Journal of Education, $10(2)$, 136-160.

Olson, P. (1985). Whose medium, whose message? Teachers, students, and equality in computer implementation. Paper presented at the Annual Conference of the American Educational Research Association, Chicago.

Postman, N. (1982). The disappearance of childhood. NewYork, NY: Delacorte.

Smith, F. (1986). Insult to intelligence: The bureaucratic invasion of our classrooms. New York, NY: Arbor House.

Turkle, S. (1984). The second self Computers and the human spirit, New York, NY: Simon \& Schuster. 
Turkle, S. (1985). Computers and the human spirit; The new computer kids. Transcript of interviews with Robert Fulford on T.V. Ontario's Realities. Toronto, ON.

AUTHOR

Randle W. Nelsen is a professor in the Department of Sociology, Lakehead University, Thunder Bay, Ontario P7B 


\title{
Saying "YES" to Educational Technology: A Response to Nelsen's "NO"
}

Robert J. D. Jones

\begin{abstract}
Thls article began as a review of Randle Nelsen's article Saying "No" to Computers In the Classroom. The editor felt that the readers of thls joumal might benefit from some counter-arguments raised in the review. Jones argues that educational technology does not pose a threat to education but, on the contrary, could serve to free education from its dependence on classroom based instruction.
\end{abstract}

Adjusting to new technologies is not easy McLuhan offers the following quotation from another era:

". . .this discovery of yours will create forgetfulness in the learners' souls, because they will not use their memories; they will trust to the external written characters and not remember of themselves. The specific which you have discovered is an aid not to memory, but only to reminiscence, and you give your disciples not truth, but only the resemblance of truth; they will be the hearers of many things and will have learned nothing.. ." (The Guttenberg Galaxy, 1962).

The invention is writing; the speaker was Plato. He was correct; with writing there was no more need to commit all knowledge to memory, Students no longer had to exercise their memories to the same extent. Something important was lost with this new technology. But few of us would argue that, on balance, writing was a bad invention.

While we can look back with some amusement at an earlier era's fear of new technologies, we can also observe that, 1) new educational technologies are often resisted in terms of what will be lost; and 2) the thing that will be lost is believed to be so essential that education itself is claimed to be threatened by the new technologies. This is essentially Nelsen's argument in Saying "No" to Computers in the Classroom - computers in education are depicted as part 
of a larger technological threat whose outcome is the homogenization of our culture resulting in the individual's and the community's loss of freedom and control over future development. A third observation we can make from Plato's quote is that the dire predictions are only partially true. Writingdid not replace our oral culture. It re-placed it while giving us more powerful tools with which to approach knowledge and learning. Computers can have a similar effect on education.

I disagree with many of Nelsen's ideas and his method of arguing them. Nelsen sets up straw men and then proceeds to attack them in the name of defending his vision of education. I will argue that neither his straw men nor his idealized educational system are real. Nelsen's straw men are the computer industry, computer-assisted instruction, and, at times, any new form of technology. The advantage of straw men is that you can define them any way you want (or better still, leave them undefined). Because they are evil, attacking them is good. For example, who would not oppose the "...bureaucratic and global corporations, as manufacturers of both computer hardware and the programmed-learning packages that accompany it, (who) continue to dehumanize and depersonalize school culture by shaping a knowledge industry built in their image."

It is true that a smaller number of corporations now dominate the hardware market compared to the early days of personal computing. Most computer users, including educators, benefit from this trend away from unique and incompatible computer systems. In any case it is not computer hardware which poses a threat to education since the hardware is meaningless without software.

So where is the threat? There was a period in the late nineteen sixties where some large corporations did look enviously at the whole education budget and sought to obtain some of this by establishing a "knowledge industry." But they quickly learned that very little of that budget was available for new technologies. I am not aware of any corporation, global or local, which has had any substantial financial or other success producing educational software, let alone materials which "dehumanize and depersonalize school culture by shaping a knowledge industry built in their image."

The reality is that the educational software industry is small and fragmented. This is partly because the amount of money spent on educational software is small compared to the amounts spent on other software (e.g., wordprocessors), on computer hardware, on other media such as textbooks, and, especially, compared to the entire educational budget. This straw man doesn't exist. If Nelsen is concerned about the threat of large corporations and homogeneity in education he should look elsewhere such as textbook publishingor school bus transportation. (Although school buses are not an educational technology per se, they are a means of bringing the student to the instruction rather than the reverse, they have a major impact on the sense of community which Nelsen feels is threatened by computers, they consume a much larger share of the educational budget than all the educational media, including 
books, and they are increasingly controlled by a small number of corporations).

In preparing for his attack on computers in education, Nelsen examines other communications technologies to illustrate the "technological drift" towards cultural homogenization which threatens individual as well as community freedoms. As an example, he is critical of the commercials which interrupt televised basketball games. But this is not an attribute of television technology: it is the product of the social and economic context which has shaped television broadcasting in North America.

When Nelsen does focus on the technology itself, his arguments are only as revealing as any truism. For example, he complains that television forces the viewer to see a game from the restricted angles imposed by the camera and thereby "miss much of the play off the ball as well as, and most importantly, the gestalt of seeing both the on-ball and off-ball interaction live or together as one moment,"making the TV experience qualitatively different from that of the onsite spectator. Who could disagree with this? It is an essential property of any tool that as it magnifies one capability, it simultaneously restricts others. We may as well complain that microscopes prevent biologists from viewing complex environmental interactions. The positive side of television is that it extends theviewer through space and time to see and hear the basketball game played across town or across the world at that very moment, or years ago, or in slow motion minutes ago in the case of delayed playback. Some things are lost in this process but other things are gained.

Nelsen next raises the "good old days" argument against new technologies. He complains that new technologies have changed the nature of music compared to that contained in his collection of 1950's recordings. The artist, he argues, is becoming a technologist, But, the artist has always been a technologist, Art has always been shaped to some degree by its tools, and part of the artist's talent has always been to master his/her craft as well as extend beyond the limitations it imposes. The 1950's electric guitarist on Nelsen's recordings was very different from the renaissance musician strumming a mandolin who was different from the hunter plucking a bow to make music. Each could complain, with some legitimacy, that yesterday's music was better and that their art was corrupted by the new technology. But invariably, artists are the ones who embrace new technologies so as to explore how to extend their art. It's the non-artist who most often complains about the loss, who argues that photography and film are not "real" art like painting and drama. Are we being set up for the argument that computer-based learning is not as real as bookbased learning which, in turn, is inferior to memorising your elder's stories?

After examining the threats in other technologies, Nelsen turns to the use of computers in education. He presents the "drill and test"mode of CAI against a backdrop of an educational system characterized by ... the interconnections among collaboration in, demonstration of, and the fredom one has in controlling her/his own learning." I agree that drill and practice software is sometimes objectionable and that too many computer-based learning packages fall into this category, But drill and practice is only one form that computer-based 
learning may take. Dismissing computers in education on this basis is like dismissing all books because some school books are spellers and workbooks.

Drill and practice as a mode of instruction pre-dates computers. Many of us learned to spell, multiply and type efficiently this way Musicians still spend hours practicing scales so as to achieve the level of craftsmanship needed to express their artistry, The point is that drill and practice has a place in education and in the educational use of computers. It would be just as wrong to make it the predominant mode of instruction as it would be to eliminate it altogether.

Nelsen's describes computer-assisted instruction as "production-line schooling," "bits and pieces learning," "fragmented, isolating and tightly controlled learning which treats human beings like pigeons pecking at keys." I don't know what Nelsen has seen, but I have seen very little of this type of computer-assisted instruction. If anything, CAI is more noted by its absence than its presence in schools. The reason for this is no longer the lack of computer hardware or software. The number of computers in North American schools is impressive. The amount and quality of software still leaves a lot to be desired. But visit any school and you would be hardpressed to find the mechanistic learning systems described by Nelsen. As an educational technologist I am both encouraged and disheartened by this. I am glad that we do not see the world described by Nelsen (because it simply does not exist except as another straw man). On the other hand I am saddened to see that educational technologies are not better understood and adopted for the positive learning experiences they could provide.

Nelsen is correct in his observation that the "personal computer revolution" is not "actually creating a revolution in the sense that large-scale socioeconomic arrangements are being fundamentally altered." This is particularly true in the case of education. Maybe we are too easily influenced by media hype which is ready to label any novelty as a "revolution" (have all the kitchen-aid revolutions fundamentally altered the socio-economic arrangements between men and women in North America?).

Maybe education is more resistant to change than other sectors of our society. Or maybe our perceptions and expectations of both education and technology are unrealistic as evidenced in Nelsen's criticism of computers and romanticization of what actually takes place in a classroom, with or without computers: "the computer is becoming just another means for further ritualizing and mechanizing a top-down direction which further abridges what little freedom is left both students and teachers together to discover and satisfy their unique desires by developing their own styles of learning." Or further, "it is precisely this failure to create a social world, a world where each individual knows that $\mathrm{s} / \mathrm{he}$ as a person exists as part of a larger collectivity and is developing a meaningful voice in engaged interaction with others, which troubles me most about the widespread reliance on computers within and outside the classroom."

While it may be pleasing to romanticize schooling in a pre-computer, pre- 
television age, the reality is that the computer and television and most other technologies including print have had little fundamental effect on education. Another reality is that schooling rarely resembles Nelsen's ideal (a fact which he admits). I would like to argue that this is because one communication medium, the unamplified spoken word, continues to dominate school-based education. This medium has shaped the physical and institutional nature of schooling in such a manner that it is impossible to introduce other media without adapting them to the point that they lose their unique characteristics. They become aids in support of the dominant medium rather than independent resources in their own right. When Nelsen says that computers should not have a place in the classroom, it may very well be that the "class room" is the wrong place for a technology which is not limited by class or room (or time for that matter).

Let's examine some of the characteristics of voice communication as the dominant educational medium to determine how it has shaped schooling. Unamplified voice communication is characterized by its limited range, susceptibility to noise interference, and time-boundness. Because the spoken word is ephemeral, that is, it disappears as soon as it is spoken, the sender and receiver must be spatially and temporally proximate. Because it is susceptible to outside interference, the sender and receiver must be isolated from noise and visual distractions. This isolation can be provided by physical barriers such as walls and by social barriers such as the rules which define acceptable classroom behaviour.

An educational system designed around this medium takes on certain characteristics. Schooling consists primarily of one person in a position of authority speaking to approximately thirty other people, controlling the nature and amount of speaking among them. So as to further facilitate communication between the one and the many, homogeneity of group membership is imposed based on criteria such as subject matter, age, gender, and previous success in adapting to this environment (i.e., "passing"). If Nelsen is disturbed by the "rule-driveness" of computers, much more could be said about the schizophrenic "rule-driveness" of schooling where chewing gum, talking to a neighbour, daydreaming, reading an unprescribed book, standing or walking without permission are such severe transgressions that the student committing them is either punished by being subjected to more schooling (detention) or removed from schooling (suspension). Many of these rules can traced back to the need to control the conditions which affect voice communications.

Far from endangering education, computers and other technologies could instead liberate education by de-schooling it, by providing alternate communication channels. Whether this happens is not simply a technological question Nelsen is correct in pointing to the larger social context within which technologies are developed, adopted and adapted by institutions to support and enhance their current agendas. Education has resisted the "technological drift" that Nelsen warns about, not because it has some duty to preserve an older culture, but because it has institutionalized one medium, teacher-led 
verbal instruction, so deeply that classroom instruction has become synonymous with schooling which in turn has become synonymous with education. If we wish to see fundamental changes in education, both of the liberalizing kind sought by Nelsen and of the empowering kind that technology can provide, we will have to start by analyzing what what is meant by media, instruction, schooling and education in the hope of generating new relationships among these concepts.

\section{AUTHOR}

Robert J. D. Jones is the Coordinator of the Courseware Design and Production program at Sheridan College in Oakville, Ontario. 


\title{
Microware Review
}

\section{Authorware Professional: Part 1}

\author{
Len Proctor
}

Best Course of Action, now known as Authorware Professional, is a design system and a courseware authoring system that has been developed for the educator-author who wishes to branch out into the design and development of computer-based instruction. Contrary to other similar systems, it is not necessary to start building course structures in any particular sequence. Instead, with the help of design icons, authors can begin where they feel comfortable and move backward or forward in the course in whatever manner they feel is appropriate. Authorware Professional automatically maintains the hierarchical structure necessary for easy course documentation, maintenance and modification. The ability of this courseware authoring system to manage "human variables" is a significant step forward in facilitating the local development of computer-based instruction.

Authorware Professional runs on a Macintosh Plus, SE, or any of the II series computers that have been equipped with a minimum of 1 Mbyte of RAM memory for monochrome systems or 2 Mbytes of memory for color systems. Two $800 \mathrm{~K}$ drives are sufficient for smaller courseware development projects but a hard disk drive is definitely recommended for modest to large projects because of the ease and increased speed with which files may be accessed. Special hardware has been included in the package for sound digitization, but it is not required for sound playback. In addition, an advanced animation module, videodisc, CDI, and CD-ROM interfaces, and cables necessary to port courseware over to an MS-DOS platform have also been provided in the system package. One major advantage of Authorware Professional now has over its previous versions is that special runtime student course disks are no longer required for course packaging. Courseware authors can now prepare their own student disks. While the purchase price for professional courseware developers has been adjusted accordingly, educational institutions can still obtain the program a substantial discount. Author-ware Professional is available from Author-ware Inc., 8500 Normandale Lake Boulevard, Ninth Floor, Minneapolis, Minnesota, 55437. 
One key question to be asked when reviewing any courseware authoring system is: "How well does the authoring environment facilitate or constrain the educator-author in the overall design and development process?" The collaborative evaluation model, developed by Collis \& Gore (1987) to help answer this question, rests on the assumption that if an “. . . integrated set of software engineering, instructional design and collaboration principles can be taken as an appropriate basis for educational software development, we claim it is also reasonable to use the same set of principles as the theoretical foundation of an evaluation model for authoring environment..." (Collis \& Gore, 1987, p. 14)

Part one of this review uses the principles identified by Collis and Gore (1987) as the basis for evaluating Authorware Professional. Part two of this review, to be published in a subsequent issue of this journal, will present the unique features of this authoring system which help to make it a flexible and versatile, stand-alone courseware development tool.

\section{Principles Reflecting the Needs of the Software Engineer}

The first question asked by Collis and Gore (1987), 'Does the system stimulate or encourage adequate attention to design before using the authoring package for technical implementation?', is answered the program's Reference Manual. Authors are encouraged to begin Using Authorware Professional in the design phase of courseware development in order to explore design ideas and experiment with a variety of options that are available. It cautions the author against attempting to complete a pencil-and-paper storyboard or flowchart before experimenting with course structure. It also cautions against trying to visualize all possible student interactions before creating a few of them. Authorware Professional has been developed as a design medium as well as an authoring system. Designs can be developed and responded to, just as a student would, in less time than it would take the author to write out the specifications necessary for a programmer to implement just one small teaching scenario. In building Authorware Professional, one of the guiding principles was 'Do not penalize (an author's) lack of planning." Good ideas should be able to be taken advantage of as they arise, even if it is in the middle of courseware implementation.

Does the system stimulate or require the developer to produce the necessary and sufficient amount of documentation for each phase of the development process? Authorware Professional has addressed this most perplexing of courseware development tasks by automatically generating all of the print documentation necessary to support the courseware design. In addition, the course documentation is instantly updated whenever a design change is made. Print options include a complete course map, a listing of all cross references by sequence, title and page number, all of the text and graphics used in the screen displays, and a cross-referenced table of any variables that the author may have developed as part of the courseware design. 
For a single-developer, does the system emphasize a distinct time for design and evaluation as opposed to programming and compiling? No. One of the very attractive features of Authorware Professional is that the execution of the lesson mode can be interrupted at any time to correct text, adjust a graphic, or add/delete a frame, without losing the context of the lesson. This feature avoids the usual division between author mode and student mode and encourages author revision or refinement of the screen displays as they are encountered. Authoring computer-based instruction is, at best, a time-consuming process. This feature alone significantly helps to reduce an author's courseware development time.

Can the various components of the courseware be developed and tested independently, and linked together when convenient? Can components (modules) of the program be reused as parts of other programs? Yes. Authoring productivity is seen by Authorware Inc. as beingrelated to the ability to use and reuse basic models. A typical model consists of the logic for implementing a courseware component such as a menu or a paradigm for a particular question type. Having a library of these examples readily available can help new users learn how to use the system more quickly and save the experienced authors the time because they do not have to reinvent the model from the beginning. By using the special start/stop flags provided in run mode, models or components of the courseware can be independently developed, tested, or modified before being incorporated into the courseware.

Does the system produce software that can be conveniently altered or extended in response to specific student needs? Does the system facilitate the development of a prototype of the extended program, for evaluation and refinement of design decisions? Yes. Any screen display developed using Authorware Professional can be added to the courseware, deleted from the courseware or altered at any time in order to respond to specific student needs. Trial prototypes can be developed, tested, refined and expanded without losing any of the original effort expended in the development of the prototype.

\section{Instructional Design Principles}

Does the system, especially through its documentation, emphasize to the developer that decisions involving basic educational needs, objective and user characteristics must be adequately addressed before other decisions are confronted? No, it assumed that the author-educator is thoroughly versed in the principles of instructional design. No reference is made to any ID model in the tutorial lessons that have been developed to help the new author learn how to use the authoring system. Asubsidiary publication, now called Authorware Magazine, does publish some articles that offer guidance in the area of instructional design.

Does the system allow data to be treated independently from the main problem? Yes, for example, question banks can be developed and called at will, in any order that they are required. 
Does the system unduly influence the designer, or constrain him from implementing his methodological decisions? No. Text and graphics can remain on the screen while input from the student is being generated, or the screens maybe cleared. If the author wishes, students may review one or more previous screens or skip one or more screens forward. If authors find limitations in the program that infringe on the chosen methodology, they may choose to append their own XCMD's and XFCN's or suspend courseware execution altogether and exit to another program. After the activity has been completed, students may then jump back into the courseware at the point where they left off.

Does the system support the variety and quality of feedback appropriate for the intended user? Does the system support the capture of information on student performance that the teacher defines as useful for subsequent analysis? Yes. Random, sequential, and data-driven branchingoptions areavailable. Over 100 system variables and functions may be used to track, monitor and record student activities and responses to quizzes. Data collection is automatic and may be used to generate reports. Performance data from multiple users may also be collected and used to generate a summary analysis report.

\section{Collaboration Principles}

Does the system facilitate iterative and on-going compromises between various participants in a collaborative environment? Which of the participants in a collaborative team is the intended user of the system -the educator or the computer scientist? Is the system appropriate for the intended user? How much training is required for the user of the system before it can be used as a facilitating tool rather than a focus of attention and effort? Authorware Professional is an authoring system, design tool and programming environment. Educators, instructional designers and computer scientists, who are involved in courseware development, would each have an opportunity to put their specialties to good use. While the system is designed to attract a novice author, it is sufficiently powerful to offer an expert author an excellent courseware development environment.

For anyone familiar with using a Macintosh computer, the tutorial supplied to assist authors in learning how to use this courseware development system is easy to follow. The new computer user however will first have to learn to use the Mac, or they may find the tutorial difficult. On the other hand, the power user may choose to skip the tutorial and go directly to the Reference Manual. While the independent study option may be the only option available for learning how to use the program, a two or three day workshop setting, under the guidance of a knowledgeable leader, should be sufficient time for almost any entry level author to become familiar with the basic operation of Authorware Professional. The assumption here is that authors are successful teachers and/or instructional designers who wish to transfer their skills to a new learning environment. The focus of Authorware is to provide a powerful courseware development environment, not to teach the author basic pedagogy, 


\section{Conclusion}

In summary, Authorware Professional has met the software engineering principles and instructional design principles set out in the collaborative evaluation model outlined by Collis and Gore (1987). It does not teach instructional design, but supports the needs of instructional designers. Similarly, it does not teach computer programming, but supports computer scientists who wish to use their programming skills. Finally, the educator-author who wishes to work alone may do so, but the program is very amenable to a collaborative or collective approach to courseware development. Anyone who is about to engage in the process of courseware development would be well advised to give this product very careful consideration. In Part Two of this review, we will take a closer look at the special authoring features provided by this powerful tool.

\section{REFERENCES}

Collis, B.A., \& Gore, M. (1987) Evaluating educational software authoring environments using a model based on software engineering and instructional design principles. Canadian Journal of Educational Communication, 16(l), 11-21

\section{COLUMN EDITOR}

Len Proctor is an Associate Professor in the Department of Communications, Continuing and Vocational Education at the University of Saskatchewan in Saskatoon, Saskatchewan, S7N OWO. 
162 CJEC SUMMER 1990 


\section{Book Reviews}

A Handbook of Computer Baaed Training (2nd Edition) by Christopher Dean and Quentin Whitlock, New York, NY: Nichols Publishing, 1939. ISBN O-89397-326-2 (CDN \$40.00)

\section{Reviewed by Stephen G. Taylor}

The beginner in any field is faced with a number of problems, any of which may be overwhelming enough to discourage a person from continuing. This is certainly true of the use of computers in education. An individual moving into the field of educational technology must rapidly acquire knowledge about computer systems, while designing instruction and developing materials in this relatively new medium of instruction. There have been few guideposts to lead the newcomer. Dean and Whitlock attempted to provide some of these in their first edition of the book in 1983, by bringing together the two areas of educational technology and computing. While their main audience was the novice, they also intended the work as a reference for practitioners, managers and computer personnel. The second edition provides this service to the same audience with a somewhat updated version of the content.

The book is divided into three parts. The first section provides the reader with a mini-course on instructional design. Starting with the development of a rationale for a training programme. A discussion of objectives and criterion testing in Chapter One reminds the reader of these important steps in instructional planning. Chapter Two, Drawing up the Learning Plan, presents in a short space some valuable points to be considered in dividing content into modules, and selecting presentation methods. This chapter also introduces the reader to the influences that the trainees bring into the instructional system. The next chapter recommends the development of a rule set to define the subject matter. This is a list of the points that must be included in the lesson. Building such a list helps to define the content area, and serves as a framework 
around which to write the lesson and order the presentation of information to the learner, Further, the rule set provides a basis of discussion and agreement with the author's client, The final two chapters of the instructional design section use the programmed instruction term frame to describe the incremental steps within an instructional module. Although the use of this term seems a little out of fashion, the advice offered and forms suggested can get the newcomer truly started in the design process. At the end of the fourth chapter the reader finds the first of several checklists. This first one is for course design and provides seventeen points that should be included in an adequate training system.

Part Two of the text features an introduction to computing hardware. While this section is obviously intended for a new arrival in the field of computers, it may also be useful to the experienced reader. Like the travel guide for a familiar city, it brings a lot of information together in one place and makes it accessible. This section also provides definitions for many of the multitude of acronyms and terms that baffle the non-computer literate person. One whole chapter is dedicated to the man-machine interface, while another is involved with explaining the different types of software. This section ends with another useful checklist of about 35 major hardware aspects that need to The first two sections of the bookconsume about half of the pages and thus the second half gets to the issues surrounding its major purpose. The content here is divided over nine chapters. Initially, the computer is put into the perspective of training technology in general. The authors express their concerns that computers are often used because of their novelty to do things that are best done by other media. They use a chapter to describe the costs and benefits of computer based training and these are summarized nicely in a table at the end of chapter 12. Planning and management are the themes of the thirteenth chapter. Here the issues of using readily available software versus writing new programming are discussed. There is an introduction to authoring systems as opposed to programming languages, and a small amount of information about facilities planning. The chapter ends with another checklist.

Chapter 14 "Aspects of Screen Design" is a new chapter. While the experienced computer course developer may have developed a personal style for producing the screen format and appearance, the novice can easily become lost and spend a lot of time to produce a visually poor product. General rules are proposed in this section to deal with text and graphic presentations, colour use, and use of windows, while reinforcing the need for consistency of format throughout theprogramme and theabsenceofclutter on the screen. these rules are based on the personal experiences of the authors. The chapter is illustrated with photgraphs of typical screens and, although they are clear, they are rather difficult to look at because of the pixel appearance on the screen.

The use of on-screen questions, response analysis and replies is the subject of the fifteenth chapter. This is a complex issue and is only given a brief coverage in the book. What had been contained within a section of a chapter in the first edition has been raised to chapter status in the second. Perhaps there 
is not much new to add at this time, but it seems that there should be more. Of the remaining four chapters of the book, two focus on authoring systems. Chapter sixteen is very much like its predecessor in the earlier edition. It introduces HAL, Hypothetical Authoring Language, as a model of the authors' ideal of such a system. This reader feels that chapter sixteen might have spent more time providing a scheme for the evaluation of authoring software with an eye to helping an individual choose an appropriate way to build instructional programmes. Chapter ninteen is a survey of 21 authoring languages. It seems strangely out of place, and while the information is useful, it might have been relegated to an appendix.

Two sections, each contained in a chapter, are given short shrift in this book. Testing and evaluation of the product of the development process are important aspects in an educational technology approach to teaching. There is a wealth of information on this topic and yet only eight pages are dedicated to covering it here, with very little new information 2nd edition. Likewise, the use of the computer for the management of the instructional process is not well covered. The major uses for this purpose are mentioned in chapter eighteen but the reader, even the beginner, will most likely feel the need for further elaboration. The book ends with a brief summary that contains a final checklist and a list of twenty DO and DON'T statements. Again these are very useful for both beginner and experienced practitioner. There is an extensive glossary with over 200 entries, along with an appropriate index.

The book purports to be an handbook on computer based training, it is unfortunate that the half of the book dedicated to this is weaker than the sections on instructional design and computer hardware. Most engineering handbooks have a format of tables, diagrams, and graphs that make access to details easy for the practitioner. Our field is yet to be developed to that degree but the experienced user of this book would probably like to have much of the information more readily available. A gesture in this direction is the inclusion of the checklists scattered through the book. These could be made easier to find through a listing. Another aspect of the book that the North American reader may find difficult is that it is clearly oriented to the United Kingdom. This weakness particularly applies to discussions about costs and the addresses for software distributers. It is also unfortunate that the authors did not include any material on the developments in artificial intelligence, expert systems or interactive video presentations in this edition.

Over all, this book could be of potential value to several kinds of users. the book is written for the newcomer and can serve this audience well. Even its weaknesses can be overlooked from this perspective. The book could be used as a student text or reference for a course in developing instructional computing systems. An instructor planning such a course could also find value in this text as quite a complete framework for course and lesson development. While the first edition of the book probably served the experienced practitioner as a desk reference, this reader did not find enough new material to justify replacing the previous edition. The book may also be of value to individuals on 
the periphery of computer assisted learning, such as computer operating personnel and managers of departments in business and industry becoming involved in computer assisted instruction.

\section{REVIEWER}

Stephen G. Taylor is a Ph.D. candidate in Educational Technology at Concordia University, Montreal, Quebec.

Interactive Media: Working Methods and Practical Applications (1st Edition) by Diana Laurillard, England: Ellis Horwood Limited, 1987. ISBN 0-7458-0011-4 (\$68.95)

\section{Reviewed by Penelope Anne Nicholson}

The question of whether to integrate interactive media into education and training has been the center of much controversy. Issues such as the costs involved, manpower and resources needed, and the fear of the complexity of hardware and software have caused confusion and apprehension in an area where clear and accurate answers are needed. For those wishing a comprehensive insight into interactive media this book is a valuable resource. Its potential readership is vast due to the variety and levels of complexity of information presented.

The information presented throughout this book is representative of developments in interactive media for education and training today since the book was published in 1987, however, advances such as bard code access in videodisc, and compact-disc interactive (CD-I) are not discussed. Readers looking for a good background and valuable information in interactive media should not dismiss this book because it is three years old, but readers looking for only the latest advances in interactive media are advised to look elsewhere.

Through 15 chapters the reader is exposed to the work of a variety of authors who clearly present their experiences, recommendations, cautions, and opinions concerning the integration of interactive media into the classroom and workplace. All chapters are divided into subsections which are clearly marked in both the table of contents and in the chapters. Helpful illustrations are provided throughout the book, and a final section presents a descriptive background of each contributor. References are provided at the end of each chapter as well as at the end of the book. Technical information is provided and numerous examples of current videodiscs are discussed.

Some of the problem-solving discs which are discussed through their planning and production stages are the 'CALCHEM' disc (chapter 'The 
Teddy Bear's Disc' (chapter 5), the "Who Do You Think You Are Talking To?' disc (chapter 8), "The Doomsday Disc" (chapter 14), and a disc created for the English Tourist Board (chapter 15). Content ranges from skills for bus drivers to deal with difficult customers, to tourist orientation to hotels and attractions in Britain.

The majority of chapters focus on interactive video with topics such as the selection of hardware and software, problems to avoid and helpful hints to use when setting up interactive videodisc projects, the issue of which level of interactivity to implement, and the potential of incorporating Conversation Theory into interactive video activities. The chapters which were of the greatest interest to me as an Educational Technologist, those concerned with the implementation and use of interactive media in the classroom, were chapters one, five, six and thirteen,

In chapter one ("Setting up an interactive videodisc project") Robert Fuller discusses video-disc based Physics lessons and provides very clear and helpful guidelines to follow when starting an interactive video project. Dr. Laurillard, in chapter five ("Pedagogoical design for interactive video"), situates interactive video in the realm of Educational Technology and stresses the importance of evaluation of interactive media. In chapter six ("Why do instructional designers need conversation theory?") Gary Boyd and Gordon Paskdiscuss the use of conversation Theory in the instructional design of interactive media. They believe that interactive video supplies one with a medium which can store and retrieve vast amounts of information, but that this information needs to brought together in well formed dialogue to be truly educational. In chapter thirteen ("Interactive video as a school resource: Rolls-Royce or Model T Ford?") Colin Mably discusses the general day-to-day usability of interactive video in the schools and focuses on considerations such as price, fears of some of the introduction of new technological innovations into the schools, potential school uses, and technical information regarding software and hardware use.

There is not one individual chapter in this book that I would single out as weak, however thebooksuffers from an unfortunate weakness of organization. The book is divided into two parts; the first deals with "Instructional Design and Development for Interactive Media", while the second deals with "Exploiting the Technology". Though the chapters in each of these sections fall under the stated headings and the text is informative, the arrangement of these chapters is not well thought out. The reader progresses through technical chapters, followed by chapters which present introductory information, which are again followed by technical chapters. It is not a practical suggestion to recommend the reader read the chapters out of sequence, but I feel it is necessary to warn readers that the ordering of chapters does not progress logically from simple and introductory information to more complex information.

This book is aimed at a wide audience and provides the reader with information about planning, producing, utilizing, applying, and evaluating interactive media, as well as information on hardware, and fundamental 
aspects of interactivity Though I feel the arrangment of chapters is not well planned, this book provides the reader with a look into the past, a sense of the present, and a clearer insight into the future of interactive media.

\section{REVIEWER}

Penelope Anne Nicholson is a Ph.D. candidate in Educational Technology at Concordia University, Montreal, Quebec. 


\section{Information for Authors}

CJEC welcomes papers on all aspects of educational communication and technology. Topics Include, but are not limited to: media and computer applications in education, leaming resource centers, communication and instructional theory, Instructional design, simulation, gaming and other aspects of the use of technology In the leaming process. These may take the form of reviews of literature, descriptions of approaches or procedures, descriptions of new applications, theoretical discussions and reports of research.

\section{Manuscript Cafegorles}

Manuscripts may fall Into one of two classes: General, dealing with a topic or Issue at a general level (although reference to specific instances or examples may be included), and Profiles, dealing with or describing only a specific Instance of an approach, technique, program, project, etc. A Profile may be thought of as a descriptive case study.

Most manuscripts dealing with a topic in general should Include reference to supportive literature, while manuscripts submitted to the Profile category may or may not. The Editor reserves the right to change the designation of a manuscript or to make a designation, if none has been made previously by the author. Authors interested In detemining the suitability of materials should consult past issues of CJEC or contact the Editor.

All manuscripts received by the Editor (either general or profile) will be judged for suitability, contribution, accuracy, etc. by a panel of anonymous reviewers designated at the time of submission. Nomally, the review process requires about eight weeks, There are no deadlines for the submission of manuscripts,

\section{Manusc ript Preparation}

Manuscripts should be typed on $81 / 2 \times 1$-inch ordinary white paper, All materials must be double-spaced, Including quotations and references. Include a title page on which appears the title of the manuscript, the full name of the author(s) along with position and Institutional afflllation, mailing address and telephone number of the contact author. An abstract of 75-150 words should be placed on a separate sheet following the title page. While the title should appear at the top of the first manuscript page, no reference to the author(s) should appear there or any other place in the manuscript. Elements of style, including headings, tables, figures and references should be prepared according to the Publication Manual of the American Psychological Association, 3rd Edition, 1983. Figures must be camera-ready.

\section{Submission of Manuscripts}

Send four copies of the manuscript to the Editor along with a letter stating that the manuscript is original material that has not been published and is not currently belng considered for publication elsewhere. If the manuscript contains copyright materials, the author should note this in the cover letter and indicate when letters of permission will be forwarded to the Editor. Manuscripts and editorial comespondence should be sent to: Richard A. Schwier, Canadian Journal of Educational Communication, Communications, Continuing \& Vocational Education, College of Education, University of Saskatchewan, Saskatoon, Saskatchewan, 57N OWO. 